\title{
SHEAR STRENGTHENING OF RC BEAMS WITH NSM CFRP LAMINATES: EXPERIMENTAL RESEARCH AND ANALYTICAL FORMULATION
}

\author{
S. J. E. Dias ${ }^{1}$ and J. A. O. Barros ${ }^{2}$ \\ ${ }^{1}$ Assistant Prof., ISISE, Dep. of Civil Eng., Univ. of Minho, Azurém, 4810-058 Guimarães, Portugal \\ 2 Full Prof., ISISE, Dep. of Civil Eng., Univ. of Minho, Azurém, 4810-058 Guimarães, Portugal
}

\begin{abstract}
The effectiveness of the NSM technique with CFRP laminates for the shear strengthening of RC beams with a certain percentage of steel stirrups was assessed by an extensive experimental research. In this context, the influence of the following parameters was investigated: concrete strength; percentage of existing steel stirrups; percentage and inclination of the CFRP laminates; existence of cracks when the RC beams are shear strengthened with NSM CFRP laminates. The results show that the higher is the concrete strength class the larger is the effectiveness of the NSM technique. The effectiveness of the CFRP laminates was higher in the beams with the lower percentage of steel stirrups. Inclined laminates were more effective than vertical laminates and the shear resistance of the beams has increased with the percentage of laminates. Pre-cracked RC beams shear strengthened with NSM CFRP laminates have presented a load carrying capacity similar to that of the homologous beams that were uncracked when strengthened. Taking the results obtained in the experimental research, an analytical formulation to predict the contribution of the possible distinct NSM shear strengthening configurations for the shear resistance of RC beams was developed. This analytical formulation is presented and its predictive performance is assessed.
\end{abstract}

KEYWORDS: CFRP laminates, NSM technique, Shear strengthening, RC beams, Experimental results, Analytical formulation

\section{INTRODUCTION}

Using advanced composites materials like carbon fiber reinforced polymers (CFRP), competitive structural strengthening solutions can be developed due to the high strength-to-weight ratio, high durability (non corrodible), electromagnetic neutrality, ease of handling, rapid execution with low labor, and practically unlimited availability in size, geometry and dimension of these materials [1-3]. In consequence, the strengthening techniques based on the use of CFRP composites materials have been intensively investigated and applied in cases where they constitute solutions that compete with the traditional strengthening techniques applied in reinforced concrete (RC) structures. 
A RC beam needs to be shear strengthened when is deficiently reinforced in shear, becomes subjected to higher loads, or when its shear capacity falls below its flexural capacity after have been submitted to a flexural strengthening intervention. The shear failure mode of a RC element should be avoided since it is brittle and unpredictable. Near surface mounted (NSM) with CFRP laminates is a technique that can be used for the shear strengthening of RC beams [4-6]. This technique involves the installation of narrow strips of CFRP laminates, of rectangular cross section, into thin slits open on the concrete cover of the lateral faces of the beams. The laminates are positioned orthogonally to the beam's axis, or as orthogonal as possible to the predicted direction of the shear failure crack, or to the already existing shear cracks.

Experimental research has demonstrated that the NSM technique provides higher strengthening effectiveness than the Externally Bonded Reinforcing (EBR) technique with CFRP [4, 7]. This fact is derived from the larger ratio between the CFRP-concrete bond perimeter and the cross sectional area of the CFRP element in case of NSM, and is also caused by the confinement provided by the surrounding concrete to the CFRP laminate $[7,8]$. A further advantage of the NSM technique is its ability to significantly reduce the probability of harm resulting from acts of vandalism, mechanical damages and aging effects. When NSM is used, the appearance of a structural strengthened element is practically unaffected by the strengthening intervention.

To appraise the performance of the application of NSM CFRP laminates for the shear strengthening of RC beams having a certain percentage of existing steel stirrups, an extensive experimental research was carried out. Four series of tests with $\mathrm{T}$ cross section $\mathrm{RC}$ beams were executed with the purpose of evaluating the influence of the following parameters on the effectiveness of the NSM shear strengthening technique: concrete strength, percentage of existing steel stirrups, percentage and orientation of the CFRP laminates. The strengthening intervention often involves concrete elements already cracked. To evaluate the influence, on the strengthening effectiveness, of already existing cracks when a beam is shear strengthened with NSM CFRP laminates, some of the RC beams were pre-cracked prior to their strengthening. A detailed description of the carried out experimental research, and a discussion of the obtained results are done in the present paper. Considering the results obtained in the experimental research, an analytical formulation to predict the contribution of the NSM CFRP laminates for the shear capacity of a RC beam was developed. The analytical formulation is described and its predictive performance is assessed in this paper.

\section{EXPERIMENTAL PROGRAM}

\subsection{Test series}

The experimental program is composed of four series of RC beams (series A, B, C and D). Fig. 1 represents the T cross section geometry and reinforcement detailment for each series, as well as the longitudinal geometry, loading configuration and support conditions. The general information of the tested series of beams is represented in Table 1 . 
The adopted reinforcement systems were designed to assure shear failure mode for all the tested beams. To avoid shear failure in the $L_{r}$ beam span (Fig. 1), in this span was applied steel stirrups of $6 \mathrm{~mm}$ diameter spaced at $75 \mathrm{~mm}$ ( $\phi 6 @ 75 \mathrm{~mm})$ in series A, B and C, and steel stirrups of 8 mm diameter spaced at $80 \mathrm{~mm}(\phi 8 @ 80 \mathrm{~mm})$ in series D. For each series, the differences between the tested beams are restricted to the shear reinforcement systems applied in the $\mathrm{L}_{\mathrm{i}}$ beam span. As schematically represented in Fig. 1, the laminates were distributed along the AB line, where A represents the beam's support at its "test side" and B is obtained assuming load degradation at $45^{\circ}$.

A general analysis of the data of Table 1 shows that the tested beams had percentages of longitudinal tensile steel bars $\left(\rho_{s l}\right)$ around $3 \%$ and had percentages of steel stirrups $\left(\rho_{s w}\right)$ ranging between $0.10 \%$ and $0.17 \%$. In terms of concrete, three types were basically used: concrete of low strength $\left(f_{c m}=18.6 \mathrm{MPa}\right.$, where $f_{c m}$ is the average concrete compressive strength at the age of the beams tests), concrete of medium strength $\left(f_{c m}=31.1 / 39.7 \mathrm{MPa}\right)$ and concrete of high strength $\left(f_{c m}=59.4 \mathrm{MPa}\right)$. Three orientations of the laminates with respect to the beam axis were tested, Fig. $1,\left(\theta_{f}=90^{\circ}-\right.$ vertical laminates; $\theta_{f}=45^{\circ}$ - laminates at $45^{\circ} ; \theta_{f}=60^{\circ}$ - laminates at $\left.60^{\circ}\right)$, and the levels of the CFRP percentage $\left(\rho_{f}\right)$ analyzed ranged between $0.06 \%$ and $0.19 \%$. The monitored beam span $\left(\mathrm{L}_{\mathrm{i}}\right)$ was 2.5 times the effective depth of the beam $\left(\mathrm{L}_{\mathrm{i}} / \mathrm{d}=2.5\right)$ for series $\mathrm{A}, \mathrm{B}$ and $\mathrm{C}$ and 3.3 times the effective depth of the beam $\left(\mathrm{L}_{\mathrm{i}} / \mathrm{d}=3.3\right)$ for series $\mathrm{D}$.

In series $\mathrm{A}\left(f_{c m}=31.1 \mathrm{MPa}\right)$ a particular emphasis was given to the influence of the percentage $\left(\rho_{f}\right)$ and orientation of the laminates $\left(\theta_{f}\right)$ on the shear strengthening of RC beams that have a certain percentage of steel stirrups. In fact, existing RC beams requiring shear strengthening intervention often have a certain percentage of steel stirrups. Three inclinations of laminates were tested $\left(45^{\circ}, 60^{\circ}\right.$ and $\left.90^{\circ}\right)$ and, for each inclination, three levels of the CFRP percentage $\left(\rho_{f}\right.$ $=0.06 \% ; \rho_{f}=0.09 \%$ to $0.10 \% ; \rho_{f}=0.13 \%$ to $0.16 \%$ ) were applied in RC beams with a percentage of steel stirrups of $0.10 \%\left(\rho_{s w}=0.10 \%\right)$. The highest percentage of laminates was designed to provide a maximum load similar to the one of the RC reference beam (without CFRP) reinforced with the highest reinforcement ratio of steel stirrups $\left(\rho_{s w}=\right.$ $0.24 \%$ ). For this purpose a CFRP laminate is assumed as working like a steel stirrup, but instead of considering the yield stress of the material, a stress in the laminates corresponding to a strain of $0.5 \%$ was adopted. This strain limit is a compromise between the maximum value recommended by ACI [1] for the EBR $(0.4 \%)$, and the $0.59 \%$ value obtained in pullout bending tests with NSM strengthening technique using CFRP laminates [9]. For the lowest and intermediate percentage of laminates, the spacing of laminates for each $\theta_{f}\left(90^{\circ}, 60^{\circ}\right.$ and $\left.45^{\circ}\right)$ was obtained with the purpose of providing similar contribution for the shear resistance.

Series $\mathrm{B}\left(f_{c m}=39.7 \mathrm{MPa}\right)$ had the intent of expanding the ranges of the CFRP percentage tested in series $\mathrm{A}\left(\rho_{f}=\right.$ $0.07 \%$ to $0.08 \% ; \rho_{f}=0.11 \%$ to $0.13 \% ; \rho_{f}=0.16 \%$ to $0.19 \%$ ) and to evaluate the effect of the percentage of steel stirrups $\left(\rho_{s w}\right)$ in the effectiveness of the NSM technique with CFRP laminates. For this purpose, several CFRP configurations were applied in RC beams with different $\rho_{s w}: 0.10 \%$ and $0.17 \%$. For this series of beams, and using the criterion above 
mentioned for series A, the highest percentage of laminates was designed to provide a maximum load similar to the one of the RC reference beam (without CFRP) reinforced with the highest reinforcement ratio of steel stirrups $\left(\rho_{s w}=\right.$ $0.28 \%)$. For the lowest and intermediate percentage of laminates, the spacing of laminates for each $\theta_{f}\left(90^{\circ}, 60^{\circ}\right.$ and $\left.45^{\circ}\right)$ was obtained with the purpose of providing similar contribution for the shear resistance.

Series C was carried out to appraise the possibility of the application of NSM CFRP laminates for the shear strengthening of low strength concrete beams having a certain percentage of existing steel stirrups. The average concrete compressive strength at the age of the beams tests was $18.6 \mathrm{MPa}$. Some of the CFRP configurations adopted in the beams of series B were also applied in beams of series C (the only difference between the beams of series B and C was the concrete strength). In fact, in series C five NSM shear strengthening configurations (three CFRP orientations and two levels of CFRP percentage) were applied in RC beams with a steel stirrups percentage $\left(\rho_{s w}\right)$ of $0.10 \%$ and $0.17 \%$

The effectiveness of NSM technique with CFRP laminates for the shear strengthening of high-strength concrete beams with a certain percentage of existing steel stirrups was assessed in the tests of the beams of series D. Some of the CFRP configurations adopted in the beams of series $\mathrm{B}$ and $\mathrm{C}$ were also applied in beams of series $\mathrm{D}$ (beams with $\rho_{s w}$ $=0.10 \%$ and $\rho_{s w}=0.16 \%$ ) that had an average concrete compressive strength of $59.4 \mathrm{MPa}$ at the age of the beams tests. To evaluate the influence, on the strengthening effectiveness, of already existing cracks when a beam is shear strengthened with NSM CFRP laminates, in series D some of the RC beams were pre-cracked prior to their strengthening.

The CFRP shear strengthening arrangements adopted in this experimental research are indicated in Table 2 . As an example, in Fig. 2 are represented three CFRP configurations (beams 2S-10LV-B, 2S-10LI45-B and 2S-9LI60-B) adopted in the beams of series B with $\rho_{s w}=0.10 \%(2 \mathrm{~S}-\mathrm{R}-\mathrm{B}$ is the reference beam without CFRP). In each series, and for each percentage of steel stirrups, one beam without CFRP was tested (see Table 2).

CFK 150/2000 S\&P laminates were used in the present experimental research. In series A the laminates had a crosssection of $1.4 \times 10 \mathrm{~mm}^{2}$, while in the other series the laminates had a cross-section of $1.4 \times 9.5 \mathrm{~mm}^{2}$. For each series of the tested beams, the average values of the young modulus, $E_{f}$, and the strain at failure, $\varepsilon_{f u}$, of the adopted laminates are indicated in Table 3. Using a diamond cutter, slits of about 4-5 mm width and 12-15 mm depth were opened on the concrete cover (of about $22 \mathrm{~mm}$ thickness) of the lateral faces of the beam web, according to the pre-defined arrangement for the laminates (the laminates were not anchored to the beam flange; they were restricted to the beam web). The MBrace Resin 220 [10] epoxy adhesive was used to bond the laminates to the concrete. 
The three point beam bending tests (Fig. 1) were carried out using a servo closed-loop control equipment, taking the signal read in the displacement transducer (LVDT), placed at the loaded section, to control the test at a deflection rate of $0.01 \mathrm{~mm} / \mathrm{second}$.

\subsection{Analysis of the experimental results}

\subsubsection{General behavior of a RC beam shear strengthening with NSM CFRP laminates}

Fig. 3 shows the typical relationship between the applied load and the deflection of the loaded section, $F-u$, for a RC beam shear strengthened with NSM CFRP laminates and for the corresponding reference beam. Up to the formation of the shear crack in the reference beam both beams have quite similar $F-u$ relationship. At this deflection limit the reference beam presented an appreciate decrease in the stiffness, which did not occur in the strengthened beam. In this beam a significant decrease in the stiffness only occur for a load level much higher than the one corresponding to the shear crack formation in the reference beam. This reveals that the CFRP laminates bridging the surfaces of the shear cracks offer resistance, mainly to crack opening, resulting a smaller degradation of the shear stress transfer between the faces of the crack due to aggregate interlock effect. Therefore, for deflections above the deflection corresponding to the formation of the shear crack in the reference beam, the stiffness of the strengthened beam is much higher than the stiffness of the reference beam. Thus, the CFRP shear strengthening configurations provided an increase in terms of stiffness and in terms of maximum load $\left(F_{\max }\right)$. The crack opening resisting mechanisms provided by the laminates bridging the shear cracks also contribute to increase the load at which stirrups enter in their plastic phase. In general the values of the deflection at the loaded section in correspondence to $F_{\max }$ of the strengthened beams $\left(u_{F_{\max }^{C F P}}^{C F R}\right)$ were higher than those occurred in the corresponding reference beams $\left(u_{F_{\max }}^{r e f}\right)$.

\subsubsection{The effect of pre-cracks}

Fig. 4 shows the $F-u$ relationship for the NSM beams with $\rho_{\mathrm{sw}}=0.10 \%$, where the only difference between them is restricted to the presence, or not, of pre-cracks when the strengthening intervention is applied (the $F$ - $u$ of the reference beam 3S-R-D is also included in Fig. 4).

The main difference between the behavior of strengthened beams with or without pre-cracks resides in an expected loss of initial stiffness in the pre-cracked specimens (up to the maximum load applied in the pre-cracking test that was about $240 \mathrm{kN}$ ). In the beams with pre-cracks the mobilization of the CFRP laminates started just after the opening process of the pre-cracks, while the mobilization of the CFRP laminates in the non pre-cracked beams only occurred when the shear crack has formed. However, the pre-cracking did not affect the efficacy of the NSM shear strengthening technique in terms of load carrying capacity and ultimate deflection. 


\subsubsection{Failure modes of the NSM shear strengthened beams with CFRP laminates}

The global analysis of the failure modes of the tested beams with CFRP laminates indicates that the efficacy of NSM technique for the shear strengthening of RC beams increases with the concrete strength. Three types of failure modes have essentially occurred in the strengthened beams. In the first, which occurred essentially in the beams of series $\mathrm{A}, \mathrm{B}$ and $\mathrm{C}$, the laminates failed by concrete fracture, having the concrete become adhered to the detached laminates (see Fig. 5a). In the beams with the highest percentage of CFRP the critical failure mode is governed by a group effect of the laminates that consists on the premature detachment of a concrete layer that includes the laminates (see Fig. $5 \mathrm{~b}$ and $5 \mathrm{c}$ ). This evidence indicates that the efficacy of NSM shear strengthening is limited by laminate spacing, as a recent analytical model has also confirmed [11].

The second failure mode is characterized by the sliding of CFRP laminates (interface between the CFRP and the adhesive) crossing the shear failure crack. This failure mode was observed in some beams of series D (see Fig. 5d). In this series also occurred the third failure mode: the rupture of the CFRP (see Fig. 5e). The higher concrete strength class of the beams of series D can justify these two last types of failures modes, since concrete was not so prone to fracture during the debond process of the laminates bridging the shear failure crack.

\subsubsection{Contribution of the CFRP for the shear resistance of the beams $\left(V_{f}\right)$ and evaluation of the effective strain of the} $\operatorname{CFRP}\left(\varepsilon_{f e}\right)$

The influence on the effectiveness of the NSM shear strengthening technique with CFRP laminates of parameters like concrete strength class, percentage of existing steel stirrups, percentage and orientation of the laminates will be assessed in terms of the contribution of the laminates for the shear resistance of the beam $\left(V_{f}\right)$. The effective strain in the laminates $\left(\varepsilon_{f e}\right)$, which corresponds to the level of mobilization of the CFRP when the strengthened RC beam reaches its shear capacity, was also registered and was used as an indicator of the NSM strengthening effectiveness.

The shear resistance of a strengthened beam $\left(V_{t}\right)$ was obtained considering the value of $F_{\max }$ (all of the tested beams failed by shear) and taking into account the force equilibrium equation: $V_{t}=0.6 F_{\max }$ for the beams of series $\mathrm{A}, \mathrm{B}$ and $\mathrm{C}$; $V_{t}=0.5 F_{\max }$ for the beams of series D. For each of the 49 shear strengthened beams tested in the present experimental research, Table 3 presents the values of $F_{\max }$ and $V_{t}$.

The shear capacity contributed by the CFRP $\left(V_{f}\right)$ was obtained by subtracting the shear resistance of the reference beam $\left(V_{r e f}\right)$ from the shear resistance of the strengthened beam $\left(V_{t}\right)$ :

$$
V_{t}=V_{\text {ref. }}+V_{f}
$$

In this approach it is assumed that the steel stirrups give the same contribution in the strengthened and in the corresponding reference beams. This assumption did not occur in some of the tested beams, since when these 
strengthened beams were compared to the corresponding reference beams it was observed a different level of mobilization of the steel stirrups. Fig. 6 presents two strengthened beams of series A (2S-5LI45-A and 2S-8LI45-A) where the contribution of steel stirrups for the shear resistance of the beams was less than the one occurred in the reference beam (2S-R-A). In the reference beam 2S-R-A two steel stirrups (stirrup 1, closest to the support, and stirrup 2 closest to the loaded section - see Fig. 6) crossed the shear failure crack in the web of the beam, and both contributed for the shear force transfer between the faces of this crack. In beams 2S-5LI45-A and 2S-8LI45-A the diagonal shear failure crack was only crossed by one steel stirrup (stirrup 1 in Fig. 6) in the web of the beam. In beam 2S-5LI45-A the stirrup 2 was intercepted after the above mentioned crack has progressed through the transition zone between the web and the flange (Fig. 6). Therefore, it is reasonable to assume that the level of mobilization of the stirrup 2 when $2 \mathrm{~S}$ 5LI45-A beam has reached its maximum capacity was lower than the level of mobilization of the stirrup 2 on the reference beam at its failure.

In this respect, the beam 2S-8LI45-A had a behavior similar to the beam 2S-5LI45-A. However, in this beam the distance between the section when the shear crack intercepted the web/flange transition zone and the stirrup 2 was higher than in the case of beam 2S-5LI45-A. Considering these evidences it is reasonable to admit that the contribution of the stirrup 2 in the beam 2S-8LI45-A for the resistance to the shear failure crack was marginal. The occurrence just described in the beam 2S-5LI45-A was also observed in the beams 2S-3LV-A, 2S-5LV-A, 2S-8LV-A, 2S-5LI60-A, 2S7LI60-A, 2S-7LV-B, 2S-10LV-B, 2S-7LV-C, 3S-10LV-D, 3S-5LI45-D, 3S-9LI45-D, 3S-5LI60-D, 3S-8LI60-D and 3S-5LI45F2-D. The occurrence described in the beam 2S-8LI45-A was also observed in the beams 2S-3LI45-A and 3S6LV-D. In order to take into account the different level of mobilization of the steel stirrups in the strengthened and in the corresponding reference beams it was assumed for the case of beam 2S-5LI45-A that the stirrup 2 has contributed $50 \%$ of its full capacity (yielded). For the case of the beam 2S-8LI45-A it was assumed that the stirrup 2 did not contribute for the resistance of the shear failure crack.

The $50 \%$ of the full contribution of a steel stirrup for the shear resistance is obtained by the following equation:

$$
V_{s}=0.5 \times A_{s w} \times f_{y m}
$$

where $A_{s w}$ is the cross sectional area of the two arms of a steel stirrup, and $f_{y m}$ is the average value of its stress at yield initiation.

Table 3 presents the values of the contribution of the CFRP laminates for the shear resistance of the tested beams, $V_{f}$, considering the equation (1), which is designated as scenario A, and the values of $V_{f}$ assuming the inferior contribution of steel stirrups in some strengthened beams, in agreement with the strategy described previously, that correspond to the scenario designated by $\mathrm{B}$.

The force resulting from the tensile stress in the CFRP laminates crossing the shear failure crack $\left(F_{f}\right)$ is defined as, 


$$
F_{f}=n_{f} \times A_{f v} \times f_{f e}
$$

where $f_{f e}$ is the effective stress in the laminates and is obtained multiplying the elastic modulus of the CFRP, $E_{f}$, by the effective strain, $\varepsilon_{f e}$. In equation (3) $A_{f v}$ is the cross sectional area of a "CFRP stirrup" that is formed by two lateral laminates:

$$
A_{f v}=2 \times a_{f} \times b_{f}
$$

where $a_{f}$ and $b_{f}$ are the dimensions of the laminate cross section. The number of laminates crossed by the shear failure crack $\left(n_{f}\right)$ is obtained by the equation (5) where $h_{w}$ is the web depth of the beam (equal to the length of vertical laminates), $\alpha$ is the orientation of the shear failure crack, $\theta_{f}$ is the inclination of the CFRP laminates with respect to the beam axis, and $s_{f}$ is the spacing of laminates (see Fig. 7).

$$
n_{f}=\frac{h_{w} \times\left(\cot g \alpha+\cot g \theta_{f}\right)}{s_{f}}
$$

The vertical projection of the force $F_{f}$ is the contribution of the CFRP to the shear resistance of the beam $\left(V_{f}\right)$ :

$$
V_{f}=F_{f} \times \sin \theta_{f}
$$

Considering the equations (3) to (6), the value of $V_{f}$ can be obtained from:

$$
V_{f}=h_{w} \times \frac{A_{f v}}{s_{f}} \times \varepsilon_{f e} \times E_{f} \times\left(\operatorname{cotg} \alpha+\operatorname{cotg} \theta_{f}\right) \times \sin \theta_{f}
$$

And, consequently:

$$
\varepsilon_{f e}=V_{f} /\left(h_{w} \times \frac{A_{f v}}{s_{f}} \times E_{f} \times\left(\operatorname{cotg} \alpha+\operatorname{cotg} \theta_{f}\right) \times \sin \theta_{f}\right)
$$

Adopting the values of $V_{f}$ associated to the above mentioned scenario B and considering for the inclination of the shear failure crack an angle of $45^{\circ}\left(\alpha=45^{\circ}\right)$, it was obtained, for each NSM beam, the value of the effective strain of the CFRP $\left(\varepsilon_{f e}\right)$ indicated in the last column of the Table 3.

\subsubsection{Influence of the concrete strength on the NSM strengthening effectiveness}

According to Table 4, five arrangements (solutions 1 to 5) of NSM CFRP laminates were used in RC beams that were manufactured with different concrete compressive strength $\left(f_{c m}\right)$ at the age of beam tests: $39.7 \mathrm{MPa}($ series B), 18.6 $\mathrm{MPa}$ (series C), and 59.4 MPa (series D). Four of these configurations (solutions 2 to 5) were applied in RC beams with a percentage of steel stirrups $\left(\rho_{s w}\right)$ of $0.10 \%$ (series B, C and D) and in RC beams with $\rho_{s w}=0.16 \%$ (series D) or $\rho_{s w}=$ $0.17 \%$ (series B and C). For these beams the values of the shear capacity contributed by the CFRP ( $\left.V_{f}\right)$ according to the 
scenario B are represented graphically in Fig. 8, being visible the increase of the NSM effectiveness with the increase of the concrete strength.

According to the values of Fig. 8, the average value of the $V_{f}$ for NSM arrangements adopted in beams of series B $\left(f_{c m}=39.7 \mathrm{MPa}\right), \mathrm{C}\left(f_{c m}=18.6 \mathrm{MPa}\right)$ and $\mathrm{D}\left(f_{c m}=59.4 \mathrm{MPa}\right)$ was $54.2 \mathrm{kN}, 35.4 \mathrm{kN}$ and $97.0 \mathrm{kN}$, respectively. Therefore, the average value of $V_{f}$ obtained in series D and B was, respectively, 1.5 and 2.7 times the average value of $V_{f}$ of series C. Fig. 8 also shows the tendency line for the diagram $V_{f} v s f_{c m}$ defined considering the average values of $V_{f}$ above mentioned for the three series of beams.

The average value of the CFRP effective strain $\left(\varepsilon_{f e}\right.$ obtained from equation (8), see Table 3$)$ for the strengthening configurations of the Table 4 was 5.6\%o, 3.6\%o and 9.8\%, respectively, for series B, C and D.

The results showed that the shear strengthening effectiveness of the NSM technique increases with the concrete strength of the beams to strengthen. This tendency is revealed on the load carrying capacity of the beams and on the effective strain in the CFRP laminates. However, from the obtained results it can be concluded that the NSM technique is still effective for the shear strengthening of RC beams of an average concrete compressive strength of $18.6 \mathrm{MPa}$ at the age of the beams tests, which can be considered as the lowest concrete strength class for structural purposes.

\subsubsection{Influence of the percentage of steel stirrups on the NSM strengthening effectiveness}

To estimate the influence of the percentage of existing steel stirrups in the effectiveness of the NSM shear strengthening technique using CFRP laminates, fifteen arrangements of NSM CFRP laminates (see Table 5) were applied in RC beams with $\rho_{s w}=0.10 \%$ (series B, C and D) and in beams with $\rho_{s w}=0.16 \%$ (series D) or $\rho_{s w}=0.17 \%$ (series B and C). For these beams the values of the shear capacity contributed by the CFRP $\left(V_{f}\right)$ according to the scenario B are represented graphically in Fig. 9, being visible that the amount of existing steel stirrups plays a very important role on the effectiveness of the NSM shear strengthening technique with CFRP laminates.

In fact, the effectiveness of the CFRP was higher in the beams with the lower percentage of steel stirrups analysed $\left(\rho_{s w}=0.10 \%\right)$, regardless the concrete strength class of the tested beams. However, the level of the influence of the percentage of existing steel stirrups seems to be as larger as smaller is the concrete strength. In Fig. 9 the parameter $\mathrm{R}$ represents, for each type of concrete, the ratio between the average value of $V_{f}$ obtained in the beams with the highest percentage of stirrups and the average value of $V_{f}$ obtained in the beams with the lowest percentage of stirrups (the values regarding the solutions 1 and 7 were excluded for this analysis). The value of $R$ for the beams of series $\mathrm{B}$, C and D was, respectively, $0.82,0.75$ and 0.92 , which confirms the aforementioned tendency between existing steel stirrups and concrete strength. In addition to the three points for the three types of concrete tested it was introduced the trend line for the variation of the parameter $\mathrm{R}$ with $f_{c m}$. 
The average value of the CFRP effective strain $\left(\varepsilon_{f e}\right.$ - see Table 3$)$ for the strengthening configurations of Table 5 corresponding to the RC beams with $\rho_{s w}=0.10 \%$ was $5.9 \%$, $4.1 \%$ and $10.6 \%$, respectively, for series $\mathrm{B}, \mathrm{C}$ and $\mathrm{D}$. The average value of $\varepsilon_{f e}$ for the strengthening configurations of Table 5 corresponding to the RC beams with $\rho_{s w}=0.16 \%$ (series D) and $\rho_{s w}=0.17 \%$ (series B and C) was 4.9\%o, 3.1\%o and 9.7\%o, respectively, for series B, C and D. These numbers confirm the decreases of $\varepsilon_{f e}$ with the increase of the percentage of existing steel stirrups of the beams to strengthen.

\subsubsection{Influence of percentage and orientation of the CFRP laminates on the NSM strengthening effectiveness}

According to Fig. 10a), in general for each series of tested beams an increase of the percentage of CFRP led to an increase of the beam's shear resistance. However, it was verified (Fig. 10b) a tendency to the decrease of the level of the effectiveness of the CFRP with the increase of the percentage of the CFRP.

In all the tested series of beams it was verified that, regardless the percentage of CFRP, the percentage of steel stirrups, and the concrete compressive strength, inclined laminates were more effective than vertical laminates in terms of increasing the stiffness, the maximum load, the deformation at failure, and the level of mobilization of the CFRP at failure of the beam. This is justified by the orientation of the shear failure crack that had a tendency to be almost orthogonal to the inclined laminates (Fig. 11). Furthermore, for vertical laminates the total resisting bond length of the CFRP is lower than that of was observed for the case of inclined laminates.

The relationship between the effective strain $\varepsilon_{f e}$ (Table 3) and the stiffness of the CFRP $\left(E_{f} \rho_{f}\right)$ with respect to the concrete resistance (in terms of $f_{c m}$ ) is presented in Fig. 12, where it is possible to see the better performance of the inclined laminates. The effective strain of the CFRP laminates decreases with the increase of the value of $E_{f} \rho_{f} /\left(f_{c m}\right)^{2 / 3}$. This tendency was more pronounced for the case of inclined laminates.

\section{ANALYTICAL FORMULATION}

\subsection{Strategy for the development of the analytical formulation}

The contribution of the NSM CFRP laminates for the shear capacity of a RC beam, identified by $V_{f}$, can be obtained using the equation (7). This equation is similar to that for steel shear reinforcement, but instead of the strain at yield initiation of the steel stirrups, the concept of effective strain in the laminates $\left(\varepsilon_{f e}\right)$ is adopted.

Based on the data derived from the experimental program described in this paper, the equation in order to obtain the value of the parameter $\varepsilon_{f e}$ for the possible distinct NSM shear strengthening configurations was assessed by adopting the following strategy: 
i) for each inclination of the CFRP $\left(\theta_{f}\right)$ that was investigated in the experimental program $\left(45^{\circ}, 60^{\circ}\right.$ and $\left.90^{\circ}\right)$ it was defined the equation that relates $\varepsilon_{f e}$ with the parameter $\left(E_{f} \rho_{f}+E_{s} \rho_{s w}\right) /\left(f_{c m}{ }^{2 / 3}\right)$. Thus, according the experimental results, four parameters with high influence on the behavior of a RC beam shear strengthening with NSM CFRP laminates were considered in this analytical formulation: the percentage $\left(\rho_{f}\right)$ and the orientation $\left(\theta_{f}\right)$ of the CFRP laminates; the concrete strength in terms of the average value of the concrete compressive strength in cylinders $\left(f_{c m}\right)$; and the percentage of steel stirrups $\left(\rho_{s w}\right)$. Each of these equations corresponds to the best fit of the values of $\varepsilon_{f e}$ obtained using equation (8), considering the experimental results of $V_{f}$ and $45^{\circ}$ for the orientation of the shear failure crack $(\alpha)$. In the parameter $\left(E_{f} \rho_{f}+E_{s} \rho_{s w}\right) /\left(f_{c m}^{2 / 3}\right)$ it was adopted $200 \mathrm{GPa}$ for the elasticity modulus of the steel stirrups $\left(E_{s}\right)$.

ii) based on the three equations determined in the step i), it was defined an equation that allows obtaining $\varepsilon_{f e}$ from the parameter $\left(E_{f} \rho_{f}+E_{s} \rho_{s w}\right) /\left(f_{c m}{ }^{2 / 3}\right)$ and the CFRP orientation $\left(\theta_{f}\right)$.

iii) considering the equation defined in the step ii) and using equation (7) it was possible to calculate the value of the contribution $V_{f}$ for each of the tested beams in the experimental program described in this paper. The comparison between experimental and analytical values of $V_{f}$ was done, and a safety factor was defined in order to assure that the analytical formulation provides safety predictions for $95 \%$ of the tested beams. A safe prediction means that the ratio between the experimental and the analytical value of the contribution of NSM CFRP laminates for the shear resistance of a RC beam is higher than 1.0.

\subsection{Development of the analytical formulation}

Fig. 13 shows the relationship between $\varepsilon_{f e}$ and $\left(E_{f} \rho_{f}+E_{s} \rho_{s w}\right) /\left(f_{c m}^{2 / 3}\right)$ parameter for the case of laminates at $45^{\circ}$, $60^{\circ}$ and $90^{\circ}$, when $90 \%$ of the beams tested in the experimental program that was described in the first part of this paper was considered. In fact, the following RC beams were not considered in this analysis: 5S-5LI45F-D beam for the case of $\theta_{f}=45^{\circ} ; 5 \mathrm{~S}-8 \mathrm{LI} 60-\mathrm{D}$ beam for the case of $\theta_{f}=60^{\circ} ; 2 \mathrm{~S}-3 \mathrm{LV}-\mathrm{A}, 2 \mathrm{~S}-4 \mathrm{LV}-\mathrm{B}$ and $4 \mathrm{~S}-7 \mathrm{LV}-\mathrm{C}$ beams for the case of $\theta_{f}=$ $90^{\circ}$. For these beams the obtained values of $\varepsilon_{f e}$ (see Table 3) were much higher (in two beams) or much lower (in three beams) than the values of $\varepsilon_{f e}$ determined in the remaining tested beams. In Fig. 13 the line that best fits the $\varepsilon_{f e}$ versus $\left(E_{f} \rho_{f}+E_{s} \rho_{s w}\right) /\left(f_{c m}{ }^{2 / 3}\right)$ experimental results for each inclination of the CFRP is also represented. These lines are defined from the following equations:

for the laminates at $45^{\circ}$ (Fig. 13a) 


$$
\varepsilon_{f e}=0.1685 \times\left[\left(E_{f} \rho_{f}+E_{s} \rho_{s w}\right) /\left(f_{c m}{ }^{2 / 3}\right)\right]^{-1.117}
$$

for the laminates at $60^{\circ}$ (Fig. 13b)

$$
\varepsilon_{f e}=0.153 \times\left[\left(E_{f} \rho_{f}+E_{s} \rho_{s w}\right) /\left(f_{c m}{ }^{2 / 3}\right)\right]^{-1.102}
$$

for the laminates at $90^{\circ}$ (vertical laminates) (Fig. 13c)

$$
\varepsilon_{f e}=0.5162 \times\left[\left(E_{f} \rho_{f}+E_{s} \rho_{s w}\right) /\left(f_{c m}^{2 / 3}\right)\right]^{-0.675}
$$

In equations (9), (10) and (11) $E_{f}$ and $E_{s}$ are in GPa and $f_{c m}$ is in MPa. Furthermore, $\rho_{f}$ and $\rho_{s w}$ are introduced like a ratio and not in percentage (values obtained with the equations in the footnote of Table 1 but eliminating the term 100).

Fig. 13d) presents, for the above mentioned three inclinations of the CFRP, the relationship between $\varepsilon_{f e}$ and $\left(E_{f} \rho_{f}+E_{s} \rho_{s w}\right) /\left(f_{c m}{ }^{2 / 3}\right)$ parameter according to the equations (9), (10) and (11). The minimum value of the $\left(E_{f} \rho_{f}+E_{s} \rho_{s w}\right) /\left(f_{c m}{ }^{2 / 3}\right)$ parameter for the tested beams was $0.022,0.022$ and 0.023 for the laminates at $45^{\circ}, 60^{\circ}$ and $90^{\circ}$, respectively, while the maximum value was $0.083,0.076$ and 0.062 for the laminates at $45^{\circ}, 60^{\circ}$ and $90^{\circ}$, respectively. Fig. 13d) also represents equations (9), (10) and (11) for a higher range of values of the $\left(E_{f} \rho_{f}+E_{s} \rho_{s w}\right) /\left(f_{c m}^{2 / 3}\right)$ parameter, namely 0.01 to 0.1 . Furthermore, the maximum value of $\varepsilon_{f e}$ is limited to the ultimate strain of the CFRP $\left(\varepsilon_{f u}\right)$ obtained from uniaxial tensile tests (the horizontal line in Figure 13d) represents the average value of $\varepsilon_{f u}$ of the CFRP laminates used in the experimental program).

Equations (9) to (11) have the following general format:

$$
\varepsilon_{f e}=C_{1} \times\left[\left(E_{f} \rho_{f}+E_{s} \rho_{s w}\right) /\left(f_{c m}^{2 / 3}\right)\right]^{-C_{2}}
$$

where $C_{1}$ and $C_{2}$ can be obtained as a function of the CFRP orientation $\left(\theta_{f}\right)$. In fact, considering the values of $C_{1}$ and $C_{2}$ of the equations (9), (10) and (11), respectively, for the case of $\theta_{f}$ equal to $45^{\circ}, 60^{\circ}$ and $90^{\circ}$, it is possible to define equation (13) and (14) for the parameter $C_{1}$ and $C_{2}$, respectively, both as function of the $\theta_{f}$, and with $\mathrm{R}^{2}=1$ :

$$
\begin{aligned}
& C_{1}=3.76888 \times e^{\left(-0.1160261 \theta f+0.0010437 \theta f^{2}\right)} \\
& C_{2}=0.460679 \times e^{\left(0.0351199 \theta f-0.0003431 \theta f^{2}\right)}
\end{aligned}
$$

Considering the equations (12), (13) and (14), the analytical formulation that determines the value of the $\varepsilon_{f e}$ parameter from the relevant data of the RC beam to be strengthened and the governing characteristics of the NSM CFRP laminates is: 


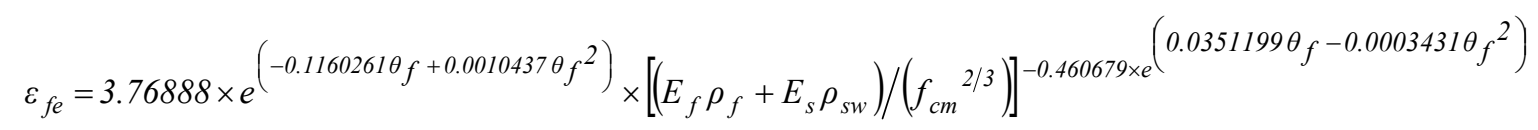

\subsection{Validation of the analytical formulation}

By using equation (15), the analytical values of the CFRP effective strain $\left(\varepsilon_{f e}^{a n a}\right)$ were determined for all the tested beams considered in the establishment of the analytical formulation. Introducing the $\varepsilon_{f e}^{a n a}$ values in equation (7), the contribution of NSM shear strengthening configurations for the shear resistance of the RC beams $\left(V_{f}^{\text {ana }}\right)$ was calculated. By considering the analytical $\left(V_{f}^{a n a}\right)$ and the experimental results $\left(V_{f}^{e x p}\right)$, the $k=V_{f}^{\exp } / V_{f}^{a n a}$ ratio was determined and is represented in Fig. 14a). For this analysis, it was considered the values of $V_{f}^{\exp }$ associated to the scenario B described in the section 2.2.4 of this paper.

Table 6 compares $V_{f}^{a n a}$ and $V_{f}^{e x p}$ values for each of the 44 RC beams shear strengthened with NSM CFRP laminates considered in the development of the present analytical formulation. The values of $V_{f}^{a n a}$ were obtained by considering the average values of the material properties. Considering this fact, in the analysis of the $k=V_{f}^{e x p} / V_{f}^{a n a}$ ratio, a $k \geq 1.0$ is synonymous of safety condition. For the Table 6 , the average value for the $k$ parameter $\left(k_{\text {med }}\right)$ was 1.01 and the corresponding standard deviation value was 0.14 .

The value of the $k_{\text {med }}$ parameter is, in fact, quite close to the unity, evidencing that in average terms the analytical model predicts with high accuracy the experimental results. However, in individual terms, some beams presented a $k$ value far below the unity (see Fig. 14a), such is the case of 2S-6LI60-B $(k=0.73), 2 \mathrm{~S}-9 \mathrm{LI} 60-\mathrm{B}(k=0.74)$ and 4S-7LV-B ( $k=0.71)$ beams. The failure modes observed in these three beams can justify their relatively low experimental value of $V_{f}$. In fact, when 2S-6LI60-B and 4S-7LV-B beams reached its maximum load capacity, there were laminates already disabled and therefore were not part of the resistance mechanism to the shear failure crack. This fact conditioned the performance of the shear strengthening solutions with NSM CFRP laminates. The maximum load of the beam 2S9LI60-B was achieved immediately before the debonding of a laminate with a reduced bond length. Although this beam has shown certain ductility, its load carrying capacity has not increased after the above mentioned debonding of the CFRP.

Since Equation (15) does not attend to all effects that influence the effectiveness of the CFRP laminates, an uncertainty factor, designated $\gamma_{f}$, is proposed (Equation (16)), having been determined in order to accomplish that $95 \%$ of the analyzed $\mathrm{RC}$ beams have a $k$ value equal or greater to the unity. Following this criterion a value of 1.3 was obtained for the $\gamma_{f}$. 


$$
\varepsilon_{f e}=\left[3.76888 \times e^{\left(-0.1160261 \theta_{f}+0.0010437 \theta_{f}^{2}\right)} \times\left[\left(E_{f} \rho_{f}+E_{s} \rho_{s w}\right) /\left(f_{c m}^{2 / 3}\right)\right]^{-0.460679 \times e^{\left(0.0351199 \theta_{f}-0.0003431 \theta_{f}^{2}\right)}}\right] / \gamma_{f}
$$

For each of the above mentioned 44 RC beams shear strengthened with NSM CFRP laminates, Table 6 presents the values of the effective strain of the CFRP $\left(\varepsilon_{f e}^{a n a}\right)$ obtained with equation (16) and the associated analytical value of $V_{f}$ ( $V_{f}^{a n a}$ ) obtained with equation (7). Considering these values of $V_{f}^{a n a}$ and the values of $V_{f}^{\exp }$, Table 6 also presents the values of the parameter $k=V_{f}^{e x p} / V_{f}^{\text {ana }}$ (see Fig. 14b). Fig. 15 compares the experimental and the analytical values of $V_{f}\left(V_{f}^{e x p}\right.$ and $V_{f}^{a n a}$, respectively) for the beams considered in the development of the analytical formulation. According to this figure, $95 \%$ of the above mentioned beams are in the safety zone (at the left side of diagonal line). Furthermore, the average value of the $k$ parameter considering the safety factor $\gamma_{f}$ equal to 1.3 was 1.31 and the corresponding standard deviation value was 0.18 .

\section{CONCLUSIONS}

In the present paper the effectiveness of the NSM shear strengthening technique with CFRP laminates applied for $\mathrm{RC}$ beams with a certain percentage of steel stirrups was assessed by an extensive experimental research. In this context, the influence of the following parameters was appraised: concrete strength; percentage of existing steel stirrups; percentage and inclination of the CFRP laminates; existence of cracks when the RC beams are shear strengthened with NSM CFRP laminates. Based on the data derived from the above mentioned experimental research, an analytical formulation for the prediction of the NSM shear strengthening contribution was developed.

From the obtained experimental results it can be concluded that the NSM shear strengthening technique with CFRP laminates is an effective technique for the shear strengthening of RC beams that contain a certain percentage of steel stirrups. The CFRP shear strengthening configurations provided an increase not only in terms of maximum load, but also in terms of load carrying capacity after shear crack formation. In general, the values of the deflection at the loaded section in correspondence to $F_{\max }$ of the strengthened beams were higher than those occurred in the corresponding reference beams.

Regardless of the percentage of CFRP, percentage of existing steel stirrups and concrete strength, it was verified that inclined laminates are more effective than vertical laminates. An increase of the percentage of CFRP led to an increase of the beam's shear resistance. The increase of the percentage of existing steel stirrups has a detrimental effect on the NSM shear strengthening effectiveness.

The main difference of the behavior of NSM CFRP beams with and without pre-cracks resides in an expected loss of initial stiffness in the pre-cracked beams. In these beams the mobilization of the CFRP laminates started just after the 
opening process of the pre-cracks, while the mobilization of the CFRP laminates in the non pre-cracked beams only occurred when the shear crack has formed. However, the pre-cracking did not affect the efficacy of the NSM shear strengthening technique in terms of load carrying capacity and ultimate deflection.

The contribution of the NSM CFRP laminates for the beam shear resistance is limited by the concrete tensile strength. In fact, this technique is more effective when applied to RC beams of high-strength concrete, not only in terms of increasing the load carrying capacity of the beams, but also in assuring higher mobilization of the tensile properties of the CFRP. However, from the obtained results it can be concluded that the NSM shear strengthening technique with CFRP laminates is still effective in RC beams made by the lowest structural concrete strength class $\left(f_{c k} \cong 12 \mathrm{MPa}\right)$.

Based on the findings of the experimental program (results of the tests of $44 \mathrm{RC}$ beams shear strengthened with NSM CFRP laminates), it was defined an equation to obtain the value of effective strain $\left(\varepsilon_{f e}\right)$. This equation is dependent of the CFRP orientation $\left(\theta_{f}\right)$ and the parameter $\left(E_{f} \rho_{f}+E_{s} \rho_{s w}\right) /\left(f_{c m}{ }^{2 / 3}\right)$ that includes the percentage of CFRP $\left(\rho_{f}\right)$, the percentage of steel stirrups $\left(\rho_{s w}\right)$ and the concrete compressive strength $\left(f_{c m}\right)$. The analytical $\left(V_{f}^{a n a}\right)$ and the experimental $\left(V_{f}^{\text {exp }}\right)$ results of the CFRP shear contribution are compared considering the ratio $k(k=$ $\left.V_{f}^{e x p} / V_{f}^{a n a}\right)$. In order to assure a safety condition $(\mathrm{k} \geq 1)$ for $95 \%$ of the analyzed beams it was introduced a safety factor equal 1.3 .

\section{ACKNOWLEDGEMENTS}

The authors wish to acknowledge the support provided by the "Empreiteiros Casais", Degussa, S\&P® and Secil (Unibetão, Braga). The study reported in this paper is part of the research project PTDC/ECM/114511/2009, supported by the Portuguese Foundation for Science and Technology (FCT).

\section{REFERENCES}

[1] ACI Committee 440, "Guide for the design and construction of externally bonded FRP systems for strengthening concrete structures”, American Concrete Institute, 118 pp. (2002).

[2] fib - Bulletin 14, "Externally bonded FRP reinforcement for RC structures”, Technical report by Task Group 9.3 FRP (Fiber Reinforced Polymer) reinforcement for concrete structures, Féderation Internationale du Béton - fib, July, 130 pp. (2001).

[3] Bakis, C.E., Bank, L.C., Brown, V.L., Cosenza, E., Davalos, J.F., Lesko, J.J., Machida, A., Riskalla, S.H. and Triantafillou, T.C., “Fiber-reinforced polymer composites for construction - state-of-the-art review”, Journal of Composites for Construction, 6(2), 73-87 (2002). 
[4] Barros, J.A.O. and Dias, S.J.E., "Near surface mounted CFRP laminates for shear strengthening of concrete beams”, Journal Cement and Concrete Composites, 28(3), 276-292 (2006).

[5] Kotynia, R., "Shear strengthening of RC beams with NSM CFRP laminates", $8^{\text {th }}$ International Symposium on Fiber Reinforced Polymer Reinforcement for Concrete Structures (FRPRCS-8), Patras, Greece, July (2007).

[6] El-Hacha, R. and Wagner, M., "Shear Strengthening of Reinforced Concrete Beams using Near-Surface Mounted CFRP Strips", $9^{\text {th }}$ International Symposium on Fiber Reinforced Polymers Reinforcement for Concrete Structures (FRPRCS-9), Sydney, Australia, July, 10 pp. (2009).

[7] El-Hacha, R. and Riskalla, S.H., "Near-surface-mounted fiber-reinforced polymer reinforcements for flexural strengthening of concrete structures”, ACI Structural Journal, 101(5), 717-726 (2004).

[8] Costa, I.G. and Barros, J.A.O., “Assessment of the bond behavior of NSM FRP materials by pullout tests”, First Middle East Conference on Smart Monitoring, Assessment and Rehabilitation of Civil Structures, Dubai, 8-10 February (2011).

[9] Sena-Cruz, J.M. and Barros, J.A.O., “Bond between near-surface mounted CFRP laminate strips and concrete in structural strengthening”, Journal of Composites for Construction, 8(6), 519-527 (2004).

[10] Degussa Construction Chemicals Portugal, Technical Report MBrace Resin 220, May (2003).

[11] Bianco, V., Barros, J.A.O., Monti, G., "New approach for modeling the contribution of NSM FRP strips for shear strengthening of RC beams”, ASCE Composites for Construction Journal, 14(1), 36-48, (2010). 


\section{TABLES AND FIGURES}

\section{List of Tables:}

Table 1 - General information about the series of the tested RC beams

Table 2 - CFRP shear strengthening configurations of the tested beams in series A, B, C and D

Table 3 - Experimental results of the 49 beams shear strengthened with NSM CFRP laminates

Table 4 - CFRP configurations applied in RC beams with three types of concrete

Table 5 - CFRP configurations applied in RC beams with two levels of the percentage of steel stirrups

Table 6 - Comparison between the experimental and analytical values

\section{List of Figures:}

Fig. 1 - General information about the tested RC beams (dimensions in $\mathrm{mm}$ )

Fig. 2 - Beams of series B with $\rho_{s w}=0.10 \%$ : the reference beam without CFRP (beam 2S-R-B) and the beams shear strengthened with the highest percentage of CFRP (dimensions in $\mathrm{mm}$ )

Fig. 3 - Behavior of RC beam shear strengthened with NSM CFRP laminates (comparison with the behavior of the corresponding reference $\mathrm{RC}$ beam)

Fig. 4 - Pre-cracking effect in terms of the force $v s$ deflection at the loaded-section

Fig. 5 - Failure modes of the RC beams shear strengthened with NSM CFRP laminates

Fig. 6 - Mobilization of steel stirrups crossing the shear failure crack: a) 2S-R-A reference beam, b) 2S-5LI45-A and 2S-8LI45-A strengthened beams

Fig. 7 - Data for the analytical definition of the effective strain of the CFRP

Fig. 8 - Influence of the concrete strength in the effectiveness of the NSM shear strengthening technique using CFRP laminates

Fig. 9 - Influence of the percentage of existing steel stirrups in the effectiveness of the NSM shear strengthening technique using CFRP laminates

Fig. 10 - Influence of the percentage of the CFRP in the effectiveness of the NSM shear strengthening technique using CFRP laminates

Fig. 11 - RC beams shear strengthened with: a) vertical and b) inclined laminates

Fig. 12 - Influence of the orientation of the CFRP in the effectiveness of the NSM shear strengthening technique using CFRP laminates 
Fig. 13 - Effective strain of the CFRP $\left(\varepsilon_{f e}\right) v s\left(E_{f} \rho_{f}+E_{s} \rho_{s w}\right) /\left(f_{c m}{ }^{2 / 3}\right)$

Fig. 14 - Values of the $k$ parameter for all the analyzed shear strengthened RC beams: a) with $\gamma_{f}=1.0$; b) with $\gamma_{f}=1.3$

Fig. 15 - Comparison between the experimental and analytical values of the CFRP contribution for the shear resistance $\left(V_{f}\right)$ 
Table 1 - General information about the series of the tested RC beams.

\begin{tabular}{|c|c|c|c|c|c|c|c|}
\hline Series & $\begin{array}{c}\rho_{f} \\
{[\%]^{(2)}}\end{array}$ & \multicolumn{3}{|c|}{$\begin{array}{c}\theta_{f} \\
{\left[{ }^{\circ}\right]}\end{array}$} & $\begin{array}{c}\rho_{s w} \\
{[\%]^{(3)}}\end{array}$ & $\begin{array}{c}f_{c m} \\
{[\mathrm{MPa}]}\end{array}$ & $L_{i} / d$ \\
\hline $\begin{array}{c}\mathrm{A} \\
\left(\rho_{s l}=2.9 \%\right)^{(1)}\end{array}$ & $\begin{array}{c}0.06 \\
0.09-0.10 \\
0.13-0.16\end{array}$ & 90 & 45 & 60 & $\begin{array}{c}0.10 \\
(\phi 6 @ 300)^{(4)}\end{array}$ & 31.1 & \multirow{5}{*}{2.5} \\
\hline \multirow{2}{*}{$\begin{array}{c}\mathrm{B} \\
\left(\rho_{s l}=2.8 \%\right)\end{array}$} & $\begin{array}{l}0.07-0.08 \\
0.11-0.13 \\
0.16-0.19\end{array}$ & \multirow[t]{2}{*}{90} & \multirow[t]{2}{*}{45} & \multirow[t]{2}{*}{60} & $\begin{array}{c}0.10 \\
(\phi 6 @ 300)\end{array}$ & \multirow[t]{2}{*}{39.7} & \\
\hline & $\begin{array}{l}0.07-0.08 \\
0.11-0.13\end{array}$ & & & & $\begin{array}{c}0.17 \\
(\phi 6 @ 180)\end{array}$ & & \\
\hline \multirow{2}{*}{$\begin{array}{c}\mathrm{C} \\
\left(\rho_{s l}=2.8 \%\right)\end{array}$} & $\begin{array}{l}0.07-0.08 \\
0.11-0.13\end{array}$ & 90 & 45 & 60 & $\begin{array}{c}0.10 \\
(\phi 6 @ 300)\end{array}$ & \multirow{2}{*}{18.6} & \\
\hline & $\begin{array}{c}0.07-0.08 \\
0.11-0.13\end{array}$ & \multicolumn{2}{|c|}{45} & 60 & $\begin{array}{c}0.17 \\
(\phi 6 @ 180)\end{array}$ & & \\
\hline \multirow{2}{*}{$\begin{array}{c}\mathrm{D} \\
\left(\rho_{s l}=3.1 \%\right)\end{array}$} & $\begin{array}{c}0.07-0.08 \\
0.11-0.13\end{array}$ & 90 & 45 & 60 & $\begin{array}{c}0.10 \\
(\phi 6 @ 300)\end{array}$ & \multirow{2}{*}{59.4} & \multirow{2}{*}{3.3} \\
\hline & $\begin{array}{l}0.07-0.08 \\
0.11-0.13\end{array}$ & \multicolumn{2}{|c|}{45} & 60 & $\begin{array}{c}0.16 \\
(\phi 6 @ 200)\end{array}$ & & \\
\hline
\end{tabular}

(1) The percentage of the longitudinal tensile reinforcement was obtained from $\rho_{s l}=\left(A_{s l} /\left(b_{w} \times d\right)\right) \times 100$ where $A_{s l}$ is the cross sectional area of the longitudinal tensile steel reinforcement (see Fig. 1), $b_{w}=180 \mathrm{~mm}$ is the width of the beam's web and $d$ is the distance from extreme compression fiber to the centroid of tensile reinforcement. (2) The CFRP percentage was obtained from $\rho_{f}=\left(\left(2 \times a_{f} \times b_{f}\right) /\left(b_{w} \times s_{f} \times \sin \theta_{f}\right)\right) \times 100$ where $a_{f}$ and $b_{f}$ are the dimensions of the laminate cross section. (3) The percentage of the vertical steel stirrups was obtained from $\rho_{s w}=\left(A_{s w} /\left(b_{w} \times s_{w}\right)\right) \times 100$ where $A_{s w}$ is the cross sectional of the arms of a steel stirrup, and $s_{w}$ is the spacing of the stirrups. (4) $\phi 6 @ 300$ means steel stirrups of $6 \mathrm{~mm}$ diameter spaced at $300 \mathrm{~mm}$ in the shear span $L_{i}$. 
Table 2 - CFRP shear strengthening configurations of the tested beams in series A, B, C and D.

\begin{tabular}{|c|c|c|c|c|c|}
\hline \multicolumn{6}{|c|}{ Series A } \\
\hline \multicolumn{2}{|c|}{$\begin{array}{c}\text { Designation of the beams } \\
\left(\rho_{s w}=0.10 \%\right) \\
\{2 \mathrm{~S}-\mathrm{R}-\mathrm{A}\}^{*}\end{array}$} & $\begin{array}{l}\text { Number of laminates } \\
\qquad\left(1.4 \times 10 \mathrm{~mm}^{2}\right)\end{array}$ & $\begin{array}{r}\theta_{f} \\
{\left[{ }^{\mathrm{o}}\right]}\end{array}$ & $\begin{array}{c}s_{f} \\
{[\mathrm{~mm}]}\end{array}$ & $\begin{array}{c}\rho_{f} \\
{[\%]}\end{array}$ \\
\hline \multicolumn{2}{|c|}{$2 \mathrm{~S}-3 \mathrm{LV}-\mathrm{A}$} & $2 \times 3$ & 90 & 267 & 0.06 \\
\hline \multicolumn{2}{|c|}{ 2S-5LV-A } & $2 \times 5$ & 90 & 160 & 0.10 \\
\hline \multicolumn{2}{|c|}{ 2S-8LV-A } & $2 \times 8$ & 90 & 100 & 0.16 \\
\hline \multicolumn{2}{|c|}{ 2S-3LI45-A } & $2 \times 3$ & 45 & 367 & 0.06 \\
\hline \multicolumn{2}{|c|}{ 2S-5LI45-A } & $2 \times 5$ & 45 & 220 & 0.10 \\
\hline \multicolumn{2}{|c|}{ 2S-8LI45-A } & $2 \times 8$ & 45 & 138 & 0.16 \\
\hline \multicolumn{2}{|c|}{ 2S-3LI60-A } & $2 \times 3$ & 60 & 325 & 0.06 \\
\hline \multicolumn{2}{|c|}{ 2S-5LI60-A } & $2 \times 5$ & 60 & 195 & 0.09 \\
\hline \multicolumn{2}{|c|}{ 2S-7LI60-A } & $2 \times 7$ & 60 & 139 & 0.13 \\
\hline \multicolumn{6}{|c|}{ Series B } \\
\hline \multicolumn{2}{|c|}{ Designation of the beams } & \multirow{2}{*}{$\begin{array}{l}\text { Number of laminates } \\
\qquad\left(1.4 \times 9.5 \mathrm{~mm}^{2}\right)\end{array}$} & \multirow[b]{2}{*}{$\begin{array}{r}\theta_{f} \\
{\left[{ }^{\mathrm{o}}\right]}\end{array}$} & \multirow[b]{2}{*}{$\begin{array}{c}s_{f} \\
{[\mathrm{~mm}]}\end{array}$} & \multirow[b]{2}{*}{$\begin{array}{c}\rho_{f} \\
{[\%]}\end{array}$} \\
\hline $\begin{array}{c}\left(\rho_{s w}=0.10 \%\right) \\
\{2 \mathrm{~S}-\mathrm{R}-\mathrm{B}\}^{*}\end{array}$ & $\begin{array}{c}\left(\rho_{s w}=0.17 \%\right) \\
\{4 \mathrm{~S}-\mathrm{R}-\mathrm{B}\}\end{array}$ & & & & \\
\hline $2 \mathrm{~S}-4 \mathrm{LV}-\mathrm{B}$ & $\begin{array}{l}4 \mathrm{~S}-4 \mathrm{LV}-\mathrm{B} * * \\
4 \mathrm{~S}-4 \mathrm{LVa}-\mathrm{B} * *\end{array}$ & $2 \times 4$ & 90 & 180 & 0.08 \\
\hline $2 \mathrm{~S}-7 \mathrm{LV}-\mathrm{B}$ & 4S-7LV-B & $2 \times 7$ & 90 & 114 & 0.13 \\
\hline $2 \mathrm{~S}-10 \mathrm{LV}-\mathrm{B}^{(1)}$ & - & $2 \times 10$ & 90 & 80 & 0.18 \\
\hline $2 \mathrm{~S}-4 \mathrm{LI} 45-\mathrm{B}$ & 4S-4LI45-B & $2 \times 4$ & 45 & 275 & 0.08 \\
\hline 2S-7LI45-B & 4S-7LI45-B & $2 \times 7$ & 45 & 157 & 0.13 \\
\hline $2 \mathrm{~S}-10 \mathrm{LI} 45-\mathrm{B}$ & - & $2 \times 10$ & 45 & 110 & 0.19 \\
\hline 2S-4LI60-B & 4S-4LI60-B & $2 \times 4$ & 60 & 243 & 0.07 \\
\hline 2S-6LI60-B & 4S-6LI60-B & $2 \times 6$ & 60 & 162 & 0.11 \\
\hline 2S-9LI60-B & - & $2 \times 9$ & 60 & 108 & 0.16 \\
\hline \multicolumn{6}{|c|}{ Series C } \\
\hline \multicolumn{2}{|c|}{ Designation of the beams } & \multirow{2}{*}{$\begin{array}{l}\text { Number of laminates } \\
\left(1.4 \times 9.5 \mathrm{~mm}^{2}\right)\end{array}$} & \multirow[b]{2}{*}{$\begin{array}{r}\theta_{f} \\
{\left[{ }^{\circ}\right]}\end{array}$} & \multirow[b]{2}{*}{$\begin{array}{c}s_{f} \\
{[\mathrm{~mm}]}\end{array}$} & \multirow[b]{2}{*}{$\begin{array}{c}\rho_{f} \\
{[\%]}\end{array}$} \\
\hline $\begin{array}{c}\left(\rho_{s w}=0.10 \%\right) \\
\{2 \mathrm{~S}-\mathrm{R}-\mathrm{C}\}^{*}\end{array}$ & $\begin{array}{c}\left(\rho_{s w}=0.17 \%\right) \\
\{4 \mathrm{~S}-\mathrm{R}-\mathrm{C}\}\end{array}$ & & & & \\
\hline $2 \mathrm{~S}-7 \mathrm{LV}-\mathrm{C}$ & $4 \mathrm{~S}-7 \mathrm{LV}-\mathrm{C}$ & $2 \times 7$ & 90 & 114 & 0.13 \\
\hline 2S-4LI45-C & 4S-4LI45-C & $2 \times 4$ & 45 & 275 & 0.08 \\
\hline 2S-7LI45-C & 4S-7LI45-C & $2 \times 7$ & 45 & 157 & 0.13 \\
\hline 2S-4LI60-C & 4S-4LI60-C & $2 \times 4$ & 60 & 243 & 0.07 \\
\hline 2S-6LI60-C & $4 \mathrm{~S}-6 \mathrm{LI} 60-\mathrm{C}^{(2)}$ & $2 \times 6$ & 60 & 162 & 0.11 \\
\hline \multicolumn{6}{|c|}{ Series D } \\
\hline \multicolumn{2}{|c|}{ Designation of the beams } & & & & \\
\hline $\begin{array}{c}\left(\rho_{s w}=0.10 \%\right) \\
\{3 \mathrm{~S}-\mathrm{R}-\mathrm{D}\}^{*}\end{array}$ & $\begin{array}{c}\left(\rho_{s w}=0.16 \%\right) \\
\{5 \mathrm{~S}-\mathrm{R}-\mathrm{D}\}^{*}\end{array}$ & $\begin{array}{l}\text { Number of laminates } \\
\qquad\left(1.4 \times 9.5 \mathrm{~mm}^{2}\right)\end{array}$ & $\begin{array}{r}\theta_{f} \\
{\left[^{\circ}\right]}\end{array}$ & $\begin{array}{c}s_{f} \\
{[\mathrm{~mm}]}\end{array}$ & $\begin{array}{c}\rho_{f} \\
{[\%]}\end{array}$ \\
\hline $3 \mathrm{~S}-6 \mathrm{LV}-\mathrm{D}$ & - & $2 \times 6$ & & 180 & 0.08 \\
\hline 3S-10LV-D & - & $2 \times 10$ & 90 & 114 & 0.13 \\
\hline 3S-5LI45-D & 5S-5LI45-D & & & & \\
\hline $3 \mathrm{~S}-5 \mathrm{LI} 45 \mathrm{~F} 1-\mathrm{D} * * *$ & 5S-5LI45F-D ${ }^{(3)}$ & $2 \times 5$ & & 275 & 0.08 \\
\hline $3 \mathrm{~S}-5 \mathrm{LI} 45 \mathrm{~F} 2-\mathrm{D} * * *$ & - & & 45 & & \\
\hline 3S-9LI45-D & 5S-9LI45-D & $2 \times 9$ & & 157 & 0.13 \\
\hline 3S-5LI60-D & 5S-5LI60-D & $2 \times 5$ & & 243 & 07 \\
\hline- & 5S-5LI60F-D & $2 \times 5$ & 60 & 243 & 0.07 \\
\hline 3S-8LI60-D & 5S-8LI60-D & $2 \times 8$ & & 162 & 0.11 \\
\hline
\end{tabular}

(1) In the designation 2S-10LV-B (see Fig. 2), 2S means two steel stirrups in the shear span $\mathrm{L}_{\mathrm{i}}, 10 \mathrm{LV}$ means ten vertical laminates in each face of the shear span $\mathrm{L}_{\mathrm{i}}, \mathrm{B}$ means series B.

${ }^{(2)}$ In the designation $4 \mathrm{~S}-6 \mathrm{LI} 60-\mathrm{C}, 4 \mathrm{~S}$ means four steel stirrups in the shear span $\mathrm{L}_{\mathrm{i}}, 6 \mathrm{LI} 60$ means six laminates at $60^{\circ}$ in each face of the shear span $\mathrm{L}_{\mathrm{i}}, \mathrm{C}$ means series $\mathrm{C}$.

${ }^{(3)}$ In the designation 5S-5LI45F-D, 5S means five stirrups in the shear span $\mathrm{L}_{\mathrm{i}}$, 5LI45 means five laminates at $45^{\circ}$ in each face of the shear span $\mathrm{L}_{\mathrm{i}}, \mathrm{F}$ means that the beam was pre-cracked, D means series D.

* Reference beams without CFRP. ** The same CFRP configuration was applied in two beams (the difference was the position of the laminates in the shear span $\mathrm{L}_{\mathrm{i}}$ ). $* * *$ The same CFRP configuration was applied in two pre-cracked beams with $\rho_{s w}=0.10 \%$. 
Table 3 - Experimental results of the 49 beams shear strengthened with NSM CFRP laminates.

\begin{tabular}{|c|c|c|c|c|c|c|c|c|c|c|c|c|c|c|c|c|}
\hline & Beams & $\begin{array}{c}f_{c m} \\
{[\mathrm{MPa}]}\end{array}$ & $\begin{array}{c}\rho_{f} \\
{[\%]}\end{array}$ & $\begin{array}{c}E_{f} \\
{[\mathrm{GPa}]}\end{array}$ & $\begin{array}{c}\varepsilon_{f u} \\
{[\% 0]}\end{array}$ & $\begin{array}{c}\theta_{f} \\
{\left[{ }^{\circ}\right]}\end{array}$ & $\begin{array}{c}\rho_{s w} \\
{[\%]}\end{array}$ & $\begin{array}{c}\rho_{s l} \\
{[\%]}\end{array}$ & $L_{i} / d$ & $\left.\begin{array}{c}s_{f} \\
{[\mathrm{~mm}]}\end{array}\right]$ & $\begin{array}{c}a_{f} \times b_{f} \\
{\left[\mathrm{~mm}^{2}\right]}\end{array}$ & $\begin{array}{l}F_{\max } \\
{[\mathrm{kN}]}\end{array}$ & $\begin{array}{c}V_{t} \\
{[\mathrm{kN}]}\end{array}$ & $\begin{array}{c}V_{f} \\
{[\mathrm{kN}]^{(1)}}\end{array}$ & $\begin{array}{c}V_{f} \\
{[\mathrm{kN}]^{(2)}}\end{array}$ & $\begin{array}{c}\varepsilon_{f e} \\
{[\% 0]}\end{array}$ \\
\hline \multirow{9}{*}{ 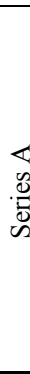 } & 2S-3LV-A & 31.1 & 0.06 & 166.6 & 17.7 & 90 & 0.10 & 2.9 & 2.5 & 267 & 14.0 & 316.0 & 189.6 & 0.6 & 15.7 & 2.99 \\
\hline & 2S-5LV-A & 1.1 & 0.10 & 166.6 & 17.7 & 90 & 0.10 & 2.9 & 2.5 & 160 & 14.0 & 357.0 & 214.2 & 25.2 & 40.3 & 4.60 \\
\hline & 2S-8LV-A & 1.1 & .16 & 166.6 & 17.7 & 90 & 0.10 & 2.9 & 2.5 & 100 & 14.0 & 396.0 & 237.6 & 48.6 & 63.7 & 4.55 \\
\hline & 2S-3LI45-A & 31.1 & 0.06 & 166.6 & 17.7 & 45 & 0.10 & 2.9 & 2.5 & 367 & 14.0 & 328.0 & 196.8 & 7.8 & 37.9 & 7.04 \\
\hline & 2S-5LI45-A & 1.1 & 0.10 & 166.6 & 17.7 & 45 & 0.10 & 2.9 & 2.5 & 220 & 14.0 & 384.0 & 230.4 & 41.4 & 56.5 & 6.28 \\
\hline & 2S-8LI45-A & 31.1 & 0.16 & 166.6 & 17.7 & 45 & 0.10 & 2.9 & 2.5 & 138 & 14.0 & 382.0 & 229.2 & 40.2 & 70.3 & 4.90 \\
\hline & 2S-3LI60-A & 31.1 & 0.06 & 166.6 & 17.7 & 60 & 0.10 & 2.9 & 2.5 & 325 & 14.0 & 374.0 & 224.4 & 35.4 & 35.4 & 6.02 \\
\hline & 2S-5LI60-A & 31.1 & 0.09 & 166.6 & 17.7 & 60 & 0.10 & 2.9 & 2.5 & 195 & 14.0 & 392.0 & 235.2 & 46.2 & 61.3 & 6.25 \\
\hline & 2S-7LI60-A & 31.1 & 0.13 & 166.6 & 17.7 & 60 & 0.10 & 2.9 & 2.5 & 139 & 14.0 & 406.0 & 243.6 & 54.6 & 69.7 & 5.07 \\
\hline \multirow{16}{*}{$\begin{array}{l}n \\
0 \\
0 \\
\tilde{D}\end{array}$} & $-4 L V-B$ & 39.7 & 8 & 170.9 & 16.0 & 90 & 0 & 2.8 & 2.5 & 180 & 3 & 337.4 & 202.4 & 20.2 & 20.2 & 2.66 \\
\hline & 2S-7LV-B & 39.7 & 0.13 & 170.9 & 16.0 & 90 & 0.10 & 2.8 & 2.5 & 114 & 13.3 & 374.1 & 224.5 & 42.2 & 57.5 & 4.81 \\
\hline & 2S-10LV-B & 3 & 0.18 & 170.9 & 16.0 & 90 & .10 & 2.8 & 4 & 80 & 3 & 397.5 & 238.5 & 56.2 & 71.5 & 4.20 \\
\hline & 2S-4LI45-B & 39.7 & 0.08 & 170.9 & 16.0 & 45 & 0.10 & 2.8 & 2.5 & 275 & 13.3 & 392.8 & 235.7 & 53.4 & 53.4 & 7.61 \\
\hline & 2S-7LI45-B & 39.7 & 0.13 & 170.9 & 16.0 & 45 & 0.10 & 2.8 & 2.5 & 157 & 13.3 & 421.7 & 253.0 & 70.7 & 70.7 & 5.76 \\
\hline & 2S-10LI45-B & 39.7 & 0.19 & 170.9 & 16.0 & 45 & 0.10 & 2.8 & 2.5 & 110 & 13.3 & 446.5 & 267.9 & 85.6 & 85.6 & 4.88 \\
\hline & 2S-4LI60-B & 39.7 & 0.07 & 170.9 & 16.0 & 60 & 0.10 & 2.8 & 2.5 & 243 & 13.3 & 386.4 & 231.8 & 49.6 & 49.6 & 6.46 \\
\hline & 2S-6LI60-B & 39.7 & 0.11 & 170.9 & 16.0 & 60 & 0.10 & 2.8 & 2.5 & 162 & 13.3 & 394.4 & 236.6 & 54.4 & 54.4 & 4.73 \\
\hline & 2S-9LI60-B & 39.7 & 0.16 & 170.9 & 16.0 & 60 & 0.10 & 2.8 & 2.5 & 108 & 13.3 & 412.7 & 247.6 & 65.3 & 65.3 & 3.79 \\
\hline & $4 \mathrm{~S}-4 \mathrm{LV}-\mathrm{B}$ & $39.7^{-}$ & 08 & 170.9 & 16.0 & 90 & 17 & 2.8 & & 180 & 3 & 424.5 & 254.7 & 31.9 & 31.9 & 4.21 \\
\hline & 4S-4LVa-B & 39.7 & 0.08 & 170.9 & 16.0 & 90 & 0.17 & 2.8 & 2 & 180 & 13.3 & 439.2 & 263.5 & 40.7 & 40.7 & 5.37 \\
\hline & & & & 9 & 1 & 90 & & 2.8 & & 114 & & 427.4 & .4 & 33.6 & 33.6 & 2.81 \\
\hline & 4S-4LI45-B & 39.7 & 0.08 & 170.9 & 16.0 & 45 & 0.17 & 2.8 & 2 & 275 & 13.3 & 442.5 & 265.5 & 42.7 & 42.7 & 6.08 \\
\hline & 4S-7LI45-B & 1 & & 170.9 & 16.0 & 45 & & 2.8 & & 157 & & 478.1 & 286.9 & 64.0 & 64.0 & 5.21 \\
\hline & 4S-4LI60-B & 39.7 & 0.07 & 170.9 & 16.0 & 60 & 0.17 & 2.8 & 2. & 243 & 13.3 & 443.9 & 266.3 & 43.5 & 43.5 & 5.67 \\
\hline & 4S-6LI60-B & 39.7 & 0.11 & 170.9 & 16.0 & 60 & 0.17 & 2.8 & & 162 & & 457.6 & 274.6 & 51.7 & 51.7 & 4.50 \\
\hline \multirow{10}{*}{ 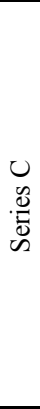 } & 2S-7LV-C & 18.6 & 0.13 & 174.3 & 16.3 & 90 & 0.10 & 2.8 & 2.5 & 114 & 13.3 & 273.7 & 164.2 & 28.3 & 43.6 & 3.57 \\
\hline & 2S-4LI45-C & 18.6 & 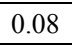 & 174.3 & 16.3 & 45 & & 2.8 & & 275 & & 283.0 & 169.8 & 33.9 & 33.9 & 4.74 \\
\hline & 2S-7LI45-C & 18.6 & 0.13 & 174.3 & 16.3 & 45 & 0.10 & 2.8 & 2 & 157 & 13.3 & 306.5 & 183.9 & 48.0 & 48.0 & 3.83 \\
\hline & 2S-4LI60-C & & 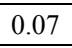 & 174.3 & 16.3 & 60 & & 2.8 & & 243 & & 281.6 & 169.0 & 33.1 & 33.1 & 4.23 \\
\hline & 2S-6LI60-C & 1 & 11 & 174.3 & 16.3 & 60. & 0 & 2.8 & 2 & 162 & 3. & 297.7 & 178.6 & 42.7 & 42.7 & 3.64 \\
\hline & 4S-7LV-C & 18.6 & 0.13 & 174.3 & 16.3 & 90 & 0.17 & 2.8 & 2. & 114 & 13.3 & 315.2 & 189.1 & 6.8 & 6.8 & 0.56 \\
\hline & 4S-4LI45-C & & 0.08 & 174.3 & 16.3 & 45 & & 2.8 & & 75 & & 347.2 & 208.3 & 26.0 & 26.0 & 3.64 \\
\hline & 4S-7LI45-C & & & 174.3 & 16.3 & 45 & & 2.8 & & 157 & & 356.4 & 213.8 & 31.6 & 31.6 & 2.52 \\
\hline & 4S-4LI60-C & 18.6 & 0.07 & 174.3 & 16.3 & 60 & & 2.8 & & 243 & & 345.6 & 207.4 & 25.1 & 25.1 & 3.21 \\
\hline & 4S-6LI60-C & 18.6 & 0.11 & 174.3 & 16.3 & 60 & 0.17 & 2.8 & 2. & 162 & 13.3 & 362.3 & 217.4 & 35.1 & 35.1 & 2.99 \\
\hline \multirow{14}{*}{. } & $-6 L V-D$ & 5 & 0.08 & 174.3 & 16.3 & 90 & & 3.1 & & 180 & & 387.0 & 193.5 & 13.6 & 44.7 & 5.79 \\
\hline & 3S-10LV-D & 59.4 & 0.13 & 174.3 & 16.3 & 90 & 0.10 & 3.1 & 3 & 114 & 13.3 & 491.7 & 245.9 & 65.9 & 81.5 & 6.68 \\
\hline & 3S-5LI45-D & 59.4 & 0.08 & 174.3 & 16.3 & 45 & 0.10 & 3.1 & 3 & 275 & 13.3 & 492.1 & 246.1 & 66.1 & 81.7 & 11.42 \\
\hline & 3S-9LI45-D & 59.4 & 0.13 & 174.3 & 16.3 & 45 & 0.10 & 3.1 & 3.3 & 157 & 13.3 & 563.6 & 281.8 & 101.9 & 117.4 & 9.37 \\
\hline & 3S-5LI60-D & 59.4 & 0.07 & 174.3 & 16.3 & 60 & 0.10 & 3.1 & 3. & 243 & 13.3 & 497.9 & 249.0 & 69.0 & 84.6 & 10.82 \\
\hline & 3S-8LI60-D & 59.4 & 0.11 & 174.3 & 16.3 & 60 & 0.10 & 3.1 & 3.3 & 162 & & 584.5 & 292.3 & 112.3 & 127.9 & 10.90 \\
\hline & 3S-5LI45F1-D & 59.4 & 0.08 & 174.3 & 16.3 & 45 & 0.10 & 3.1 & 3. & 275 & 13.3 & 531.4 & 265.7 & 85.8 & 85.8 & 11.99 \\
\hline & 3S-5LI45F2-D & 59.4 & 0.08 & 174.3 & 16.3 & 45 & 0.10 & 3.1 & 3.3 & 275 & 13.3 & 490.6 & 245.3 & 65.4 & 80.9 & 11.31 \\
\hline & 5S-5LI45-D & 59.4 & 0.08 & 174.3 & 16.3 & 45 & 0.16 & 3.1 & 3.3 & 275 & 13.3 & 559.5 & 279.8 & 74.9 & 74.9 & 10.47 \\
\hline & 5S-9LI45-D & 59.4 & 0.13 & 174.3 & 16.3 & 45 & 0.16 & 3.1 & 3.3 & 157 & 13.3 & 627.5 & 313.8 & 108.9 & 108.9 & 8.69 \\
\hline & 5S-5LI60-D & 59.4 & 0.07 & 174.3 & 16.3 & 60 & 0.16 & 3.1 & 3.3 & 243 & 13.3 & 556.4 & 278.2 & 73.4 & 73.4 & 9.38 \\
\hline & 5S-8LI60-D & 59.4 & 0.11 & 174.3 & 16.3 & 60 & 0.16 & 3.1 & 3.3 & 162 & 13.3 & 654.6 & 327.3 & 122.5 & 122.5 & 10.44 \\
\hline & 5S-5LI45F-D & 59.4 & 0.08 & 174.3 & 16.3 & 45 & 0.16 & 3.1 & 3.3 & 275 & 13.3 & 611.9 & 306.0 & 101.1 & 101.1 & 14.13 \\
\hline & 5S-5LI60F-D & 59.4 & 0.07 & 174.3 & 16.3 & 60 & 0.16 & 3.1 & 3.3 & 243 & 13.3 & 554.8 & 277.4 & 72.6 & 72.6 & 9.28 \\
\hline
\end{tabular}

${ }^{(1)}$ Values obtained considering the scenario A. ${ }^{(2)}$ Values obtained considering the scenario B. 
Table 4 - CFRP configurations applied in RC beams with three types of concrete.

\begin{tabular}{|c|c|c|c|c|c|c|c|}
\hline \multirow{2}{*}{$\begin{array}{c}\text { CFRP } \\
\text { configuration }\end{array}$} & \multirow[b]{2}{*}{$\begin{array}{l}\rho_{s w} \\
{[\%]}\end{array}$} & \multirow[b]{2}{*}{$\begin{array}{c}\rho_{f} \\
{[\%]}\end{array}$} & \multirow{2}{*}{$\begin{array}{r}\theta_{f} \\
{\left[{ }^{\circ}\right]}\end{array}$} & \multirow{2}{*}{$\begin{array}{c}s_{f} \\
{[\mathrm{~mm}]}\end{array}$} & \multicolumn{3}{|c|}{ Beams } \\
\hline & & & & & $\begin{array}{c}\text { Series B } \\
\left(f_{c m}=39.7 \mathrm{MPa}\right)\end{array}$ & $\begin{array}{c}\text { Series C } \\
\left(f_{c m}=18.6 \mathrm{MPa}\right)\end{array}$ & $\begin{array}{c}\text { Series D } \\
\left(f_{c m}=59.4 \mathrm{MPa}\right)\end{array}$ \\
\hline Solution 1 & 0.10 & 0.13 & 90 & 114 & 2S-7LV-B & 2S-7LV-C & 3S-10LV-D \\
\hline Solution $2 \mathrm{a}$ & 0.10 & \multirow{2}{*}{0.08} & \multirow{2}{*}{45} & \multirow{2}{*}{275} & 2S-4LI45-B & 2S-4LI45-C & 3S-5LI45-D \\
\hline Solution $2 \mathrm{~b}$ & $0.16-0.17$ & & & & 4S-4LI45-B & 4S-4LI45-C & 5S-5LI45-D \\
\hline Solution 3a & 0.10 & \multirow{2}{*}{0.07} & \multirow{2}{*}{60} & \multirow{2}{*}{243} & 2S-4LI60-B & 2S-4LI60-C & 3S-5LI60-D \\
\hline Solution $3 b$ & $0.16-0.17$ & & & & 4S-4LI60-B & 4S-4LI60-C & 5S-5LI60-D \\
\hline Solution $4 \mathrm{a}$ & 0.10 & \multirow{2}{*}{0.13} & \multirow{2}{*}{45} & \multirow{2}{*}{157} & 2S-7LI45-B & 2S-7LI45-C & 3S-9LI45-D \\
\hline Solution $4 \mathrm{~b}$ & $0.16-0.17$ & & & & 4S-7LI45-B & 4S-7LI45-C & 5S-9LI45-D \\
\hline Solution $5 \mathrm{a}$ & 0.10 & \multirow{2}{*}{0.11} & \multirow{2}{*}{60} & \multirow{2}{*}{162} & 2S-6LI60-B & 2S-6LI60-C & 3S-8LI60-D \\
\hline Solution $5 \mathrm{~b}$ & $0.16-0.17$ & & & & 4S-6LI60-B & 4S-6LI60-C & 5S-8LI60-D \\
\hline
\end{tabular}

Table 5 - CFRP configurations applied in RC beams with two levels of the percentage of steel stirrups.

\begin{tabular}{|c|c|c|c|c|c|c|}
\hline \multirow{2}{*}{$\begin{array}{c}\text { CFRP } \\
\text { configuration }\end{array}$} & \multirow{2}{*}{$\begin{array}{c}\rho_{f} \\
{[\%]}\end{array}$} & \multirow{2}{*}{$\begin{array}{r}\theta_{f} \\
{\left[{ }^{\circ}\right]}\end{array}$} & \multirow{2}{*}{$\begin{array}{c}s_{f} \\
{[\mathrm{~mm}]}\end{array}$} & \multirow{2}{*}{ Series } & \multicolumn{2}{|c|}{ Beams } \\
\hline & & & & & $\rho_{s w}=0.10 \%$ & $\rho_{s w}=0.16 \%-0.17 \%{ }^{(1)}$ \\
\hline Solution 1 & 0.08 & 90 & 180 & $\mathrm{~B}$ & 2S-4LV-B & 4S-4LV-B \\
\hline Solution 2 & 0.13 & 90 & 114 & B & 2S-7LV-B & 4S-7LV-B \\
\hline Solution 3 & 0.08 & 45 & 275 & $\mathrm{~B}$ & 2S-4LI45-B & 4S-4LI45-B \\
\hline Solution 4 & 0.13 & 45 & 157 & $\mathrm{~B}$ & 2S-7LI45-B & 4S-7LI45-B \\
\hline Solution 5 & 0.07 & 60 & 243 & $\mathrm{~B}$ & 2S-4LI60-B & 4S-4LI60-B \\
\hline Solution 6 & 0.11 & 60 & 162 & $\mathrm{~B}$ & 2S-6LI60-B & 4S-6LI60-B \\
\hline Solution 7 & 0.13 & 90 & 114 & $\mathrm{C}$ & 2S-7LV-C & 4S-7LV-C \\
\hline Solution 8 & 0.08 & 45 & 275 & $\mathrm{C}$ & 2S-4LI45-C & 4S-4LI45-C \\
\hline Solution 9 & 0.13 & 45 & 157 & $\mathrm{C}$ & 2S-7LI45-C & 4S-7LI45-C \\
\hline Solution 10 & 0.07 & 60 & 243 & $\mathrm{C}$ & 2S-4LI60-C & 4S-4LI60-C \\
\hline Solution 11 & 0.11 & 60 & 162 & $\mathrm{C}$ & 2S-6LI60-C & 4S-6LI60-C \\
\hline Solution 12 & 0.08 & 45 & 275 & $\mathrm{D}$ & 3S-5LI45-D & 5S-5LI45-D \\
\hline Solution 13 & 0.13 & 45 & 157 & $\mathrm{D}$ & 3S-9LI45-D & 5S-9LI45-D \\
\hline Solution 14 & 0.07 & 60 & 243 & $\mathrm{D}$ & 3S-5LI60-D & 5S-5LI60-D \\
\hline Solution 15 & 0.11 & 60 & 162 & $\mathrm{D}$ & 3S-8LI60-D & 5S-8LI60-D \\
\hline
\end{tabular}

${ }^{(1)} \rho_{s w}=0.16 \%$ for the beams of series $\mathrm{D}$ and $\rho_{s w}=0.17 \%$ for the beams of series $\mathrm{B}$ and $\mathrm{C}$. 
Table 6 - Comparison between the experimental and analytical values.

\begin{tabular}{|c|c|c|c|c|c|c|c|c|}
\hline \multirow[b]{2}{*}{ Beams } & \multirow[b]{2}{*}{$\begin{array}{c}V_{f}^{\exp } \\
{[\mathrm{kN}]}\end{array}$} & \multirow[b]{2}{*}{$\begin{array}{c}\varepsilon_{f e}{ }^{(1)} \\
{[\% 0]}\end{array}$} & \multicolumn{3}{|c|}{$\gamma_{f}=1.0($ using equation $(15))$} & \multicolumn{3}{|c|}{$\gamma_{f}=1.3$ (using equation (16)) } \\
\hline & & & $\begin{array}{c}\varepsilon_{f e}^{a n a} \\
{[\% 0]}\end{array}$ & $\begin{array}{l}V_{f}^{\text {ana }} \\
{[\mathrm{kN}]}\end{array}$ & $k$ & $\begin{array}{l}\varepsilon_{f e}^{a n a} \\
{[\% 0]}\end{array}$ & $\begin{array}{l}V_{f}^{\text {ana }} \\
{[\mathrm{kN}]}\end{array}$ & $k$ \\
\hline $2 \mathrm{~S}-5 \mathrm{LV}-\mathrm{A}$ & 40.3 & 4.60 & 4.73 & 41.4 & 0.97 & 3.64 & 31.8 & 1.27 \\
\hline $2 \mathrm{~S}-8 \mathrm{LV}-\mathrm{A}$ & 63.7 & 4.55 & 4.04 & 56.6 & 1.13 & 3.11 & 43.5 & 1.46 \\
\hline 2S-3LI45-A & 37.9 & 7.04 & 8.08 & 43.6 & 0.87 & 6.22 & 33.5 & 1.13 \\
\hline 2S-5LI45-A & 56.5 & 6.28 & 6.50 & 58.4 & 0.97 & 5.00 & 45.0 & 1.26 \\
\hline 2S-8LI45-A & 70.3 & 4.90 & 5.00 & 71.8 & 0.98 & 3.85 & 55.2 & 1.27 \\
\hline 2S-3LI60-A & 35.4 & 6.02 & 7.16 & 42.1 & 0.84 & 5.51 & 32.4 & 1.09 \\
\hline 2S-5LI60-A & 61.3 & 6.25 & 5.84 & 57.3 & 1.07 & 4.49 & 44.0 & 1.39 \\
\hline 2S-7LI60-A & 69.7 & 5.07 & 4.91 & 67.5 & 1.03 & 3.78 & 52.0 & 1.34 \\
\hline 2S-7LV-B & 57.5 & 4.81 & 4.78 & 57.1 & 1.01 & 3.67 & 43.9 & 1.31 \\
\hline 2S-10LV-B & 71.5 & 4.20 & 4.18 & 71.2 & 1.00 & 3.21 & 54.8 & 1.31 \\
\hline 2S-4LI45-B & 53.4 & 7.61 & 8.74 & 61.3 & 0.87 & 6.72 & 47.1 & 1.13 \\
\hline 2S-7LI45-B & 70.7 & 5.76 & 6.59 & 80.9 & 0.87 & 5.07 & 62.3 & 1.14 \\
\hline 2S-10LI45-B & 85.6 & 4.88 & 5.26 & 92.3 & 0.93 & 4.05 & 71.0 & 1.21 \\
\hline 2S-4LI60-B & 49.6 & 6.46 & 7.77 & 59.6 & 0.83 & 5.98 & 45.8 & 1.08 \\
\hline 2S-6LI60-B & 54.4 & 4.73 & 6.47 & 74.3 & 0.73 & 4.97 & 57.2 & 0.95 \\
\hline 2S-9LI60-B & 65.3 & 3.79 & 5.14 & 88.7 & 0.74 & 3.95 & 68.2 & 0.96 \\
\hline 4S-4LV-B & 31.9 & 4.21 & 4.38 & 33.2 & 0.96 & 3.37 & 25.5 & 1.25 \\
\hline 4S-4LVa-B & 40.7 & 5.37 & 4.38 & 33.2 & 1.23 & 3.37 & 25.5 & 1.59 \\
\hline 4S-7LV-B & 33.6 & 2.81 & 3.95 & 47.3 & 0.71 & 3.04 & 36.4 & 0.92 \\
\hline 4S-4LI45-B & 42.7 & 6.08 & 5.95 & 41.7 & 1.02 & 4.57 & 32.1 & 1.33 \\
\hline 4S-7LI45-B & 64.0 & 5.21 & 4.83 & 59.4 & 1.08 & 3.72 & 45.7 & 1.40 \\
\hline 4S-4LI60-B & 43.5 & 5.67 & 5.27 & 40.4 & 1.08 & 4.05 & 31.1 & 1.40 \\
\hline 4S-6LI60-B & 51.7 & 4.50 & 4.61 & 53.0 & 0.98 & 3.55 & 40.8 & 1.27 \\
\hline $2 \mathrm{~S}-7 \mathrm{LV}-\mathrm{C}$ & 43.6 & 3.57 & 3.37 & 41.1 & 1.06 & 2.59 & 31.6 & 1.38 \\
\hline 2S-4LI45-C & 33.9 & 4.74 & 4.93 & 35.2 & 0.96 & 3.79 & 27.1 & 1.25 \\
\hline 2S-7LI45-C & 48.0 & 3.83 & 3.70 & 46.4 & 1.03 & 2.85 & 35.7 & 1.34 \\
\hline 2S-4LI60-C & 33.1 & 4.23 & 4.42 & 34.6 & 0.96 & 3.40 & 26.6 & 1.24 \\
\hline 2S-6LI60-C & 42.7 & 3.64 & 3.67 & 43.0 & 0.99 & 2.82 & 33.1 & 1.29 \\
\hline 4S-4LI45-C & 26.0 & 3.64 & 3.36 & 24.0 & 1.08 & 2.59 & 18.5 & 1.41 \\
\hline 4S-7LI45-C & 31.6 & 2.52 & 2.72 & 34.1 & 0.92 & 2.10 & 26.3 & 1.20 \\
\hline 4S-4LI60-C & 25.1 & 3.21 & 3.00 & 23.5 & 1.07 & 2.31 & 18.0 & 1.39 \\
\hline 4S-6LI60-C & 35.1 & 2.99 & 2.62 & 30.8 & 1.14 & 2.02 & 23.7 & 1.48 \\
\hline 3S-6LV-D & 44.7 & 5.79 & 6.56 & 50.7 & 0.88 & 5.04 & 39.0 & 1.15 \\
\hline 3S-10LV-D & 81.5 & 6.68 & 5.69 & 69.4 & 1.17 & 4.37 & 53.4 & 1.53 \\
\hline 3S-5LI45-D & 81.7 & 11.42 & 11.70 & 83.7 & 0.98 & 9.00 & 64.4 & 1.27 \\
\hline 3S-9LI45-D & 117.4 & 9.37 & 8.79 & 110.2 & 1.07 & 6.76 & 84.7 & 1.39 \\
\hline 3S-5LI45F1-D & 85.8 & 11.99 & 11.70 & 83.7 & 1.02 & 9.00 & 64.4 & 1.33 \\
\hline 3S-5LI45F2-D & 80.9 & 11.31 & 11.70 & 83.7 & 0.97 & 9.00 & 64.4 & 1.26 \\
\hline 3S-5LI60-D & 84.6 & 10.82 & 10.37 & 81.1 & 1.04 & 7.98 & 62.4 & 1.36 \\
\hline 3S-8LI60-D & 127.9 & 10.90 & 8.61 & 100.9 & 1.27 & 6.62 & 77.6 & 1.65 \\
\hline 5S-5LI45-D & 74.9 & 10.47 & 8.68 & 62.1 & 1.21 & 6.68 & 47.8 & 1.57 \\
\hline 5S-9LI45-D & 108.9 & 8.69 & 6.93 & 86.9 & 1.25 & 5.33 & 66.8 & 1.63 \\
\hline 5S-5LI60-D & 73.4 & 9.38 & 7.66 & 59.9 & 1.22 & 5.90 & 46.1 & 1.59 \\
\hline 5S-5LI60F-D & 72.6 & 9.28 & 7.66 & 59.9 & 1.21 & 5.90 & 46.1 & 1.57 \\
\hline
\end{tabular}

${ }^{(1)}$ Effective strain of the CFRP obtained with Eq. (8) considering $V_{f}^{\exp }$ and $\alpha=45^{\circ}$. 


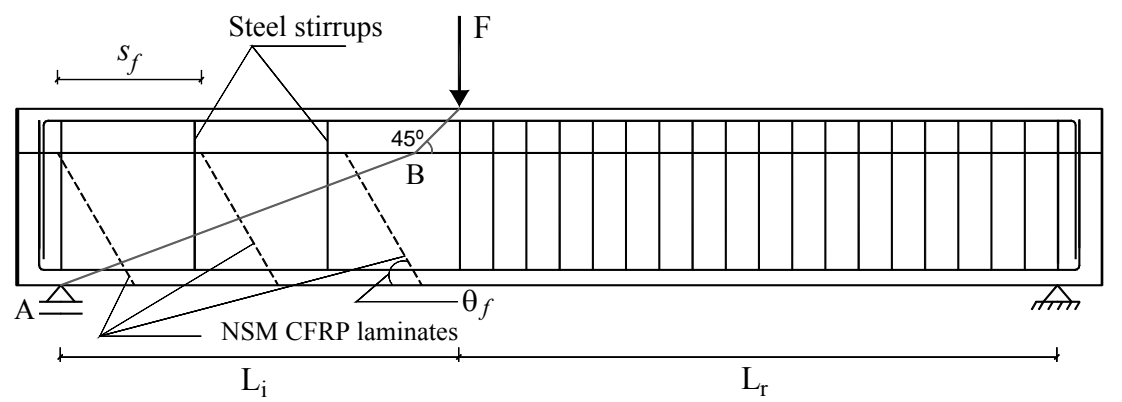

Series A, B and C: $\mathrm{L}_{\mathrm{i}}=900 \mathrm{~mm}$ Series $D: L_{i}=1200 m$

Series A, B and C: $L_{r}=1350 \mathrm{~mm}$ Series D: $\mathrm{L}_{\mathrm{r}}=1200 \mathrm{~m}$

\begin{tabular}{|c|c|c|c|}
\hline Series $\mathrm{A}$ & Series $\mathrm{B}$ and $\mathrm{C}$ & Series D \\
$\varnothing 66 / 300$ in $\mathrm{L}_{\mathrm{i}}$ & &
\end{tabular}

Fig. 1 - General information about the tested RC beams (dimensions in $\mathrm{mm}$ ). 


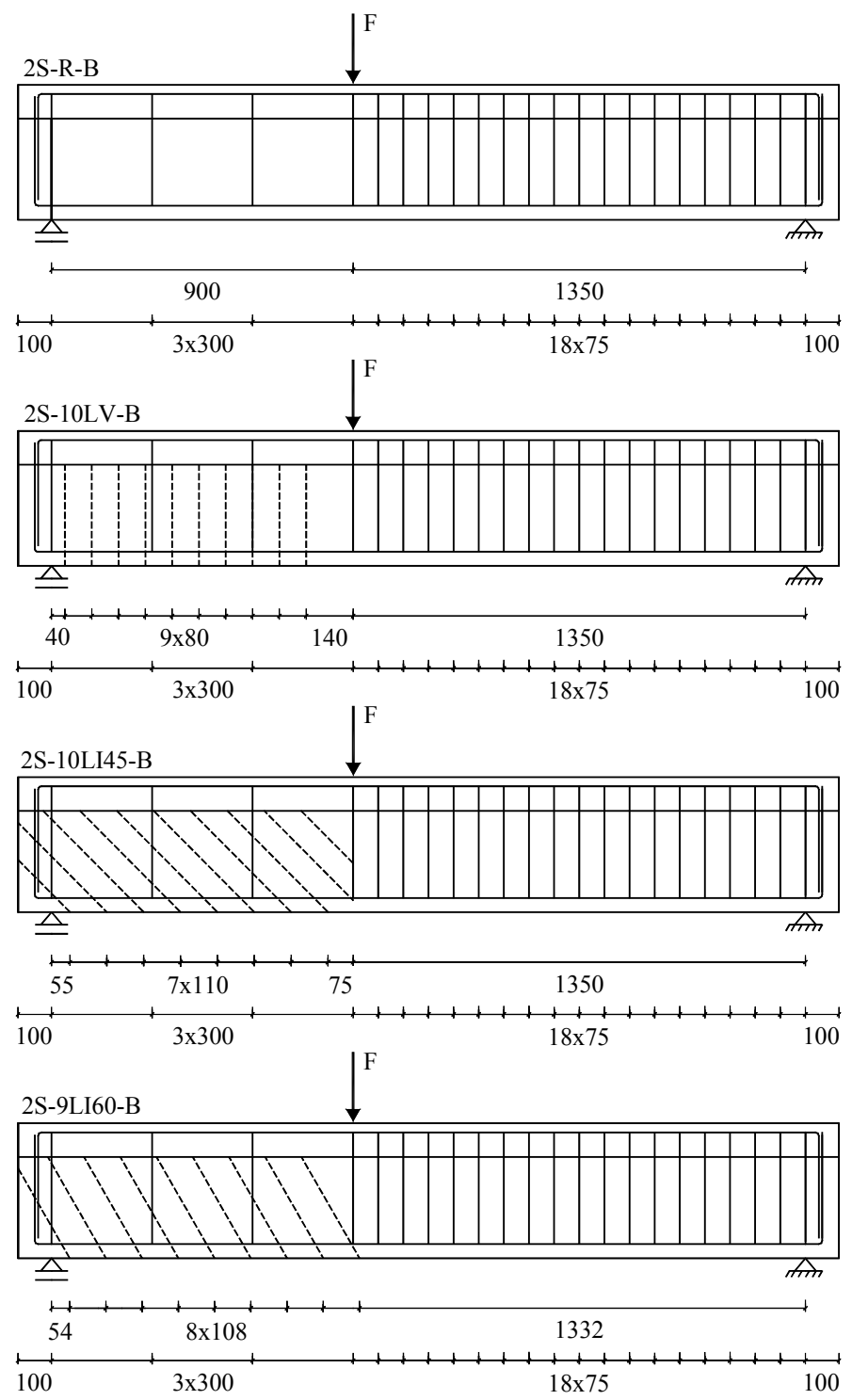

Fig. 2 - Beams of series B with $\rho_{s w}=0.10 \%$ : the reference beam without CFRP (beam 2S-R-B) and the beams shear strengthened with the highest percentage of CFRP (dimensions in $\mathrm{mm}$ ). 

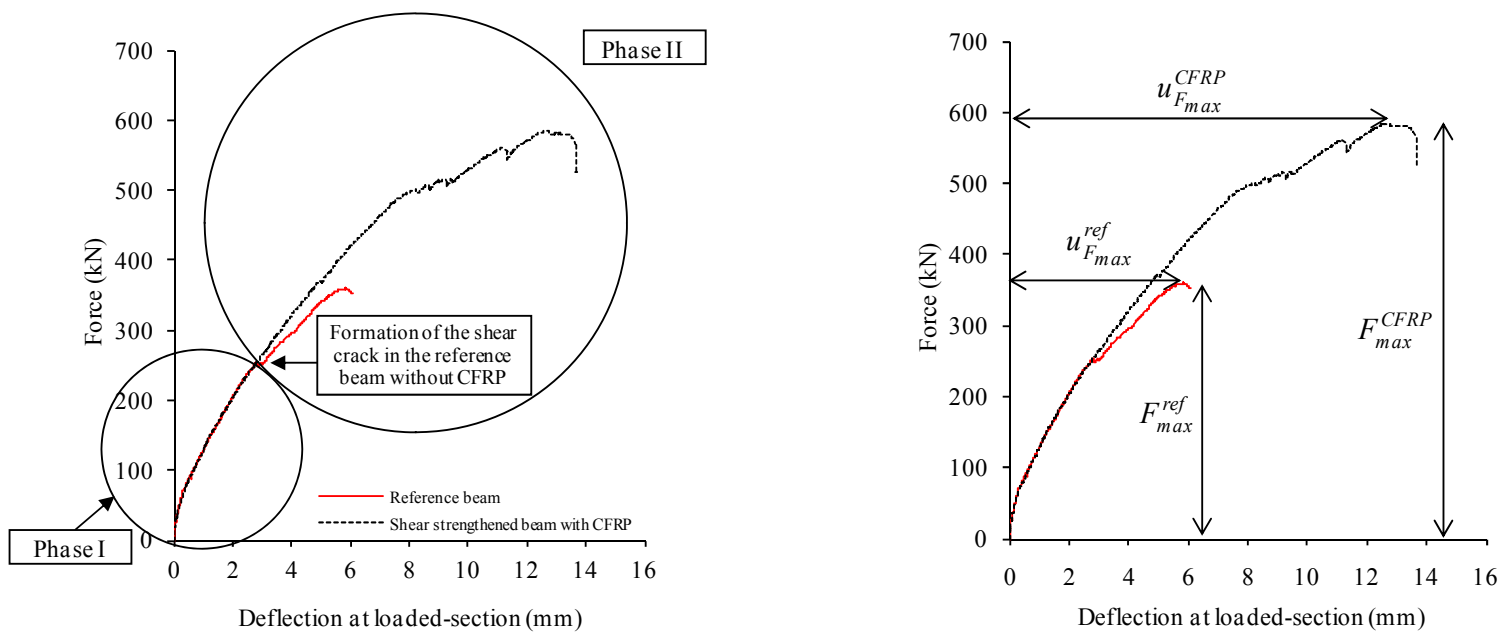

Fig. 3 - Behavior of RC beam shear strengthened with NSM CFRP laminates (comparison with the behavior of the corresponding reference $\mathrm{RC}$ beam).

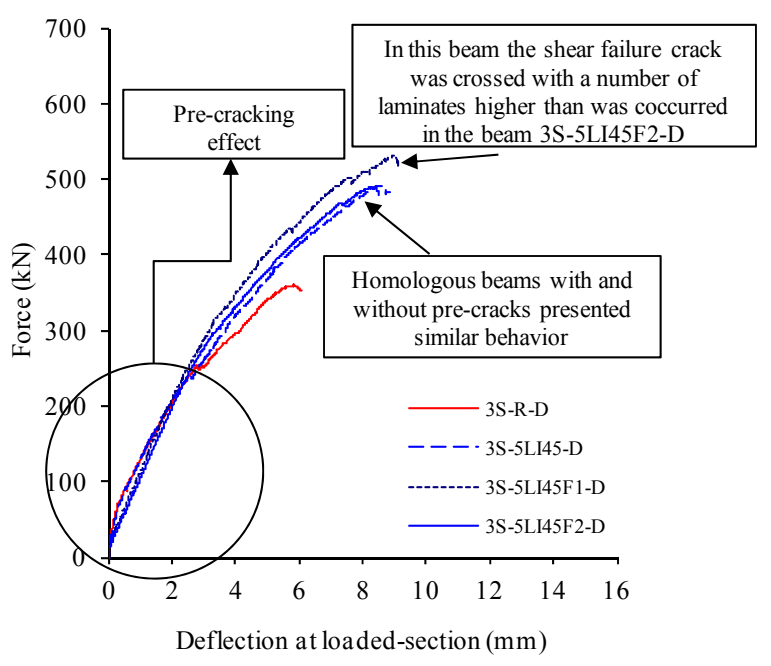

Fig. 4 - Pre-cracking effect in terms of the force $v s$ deflection at the loaded-section. 


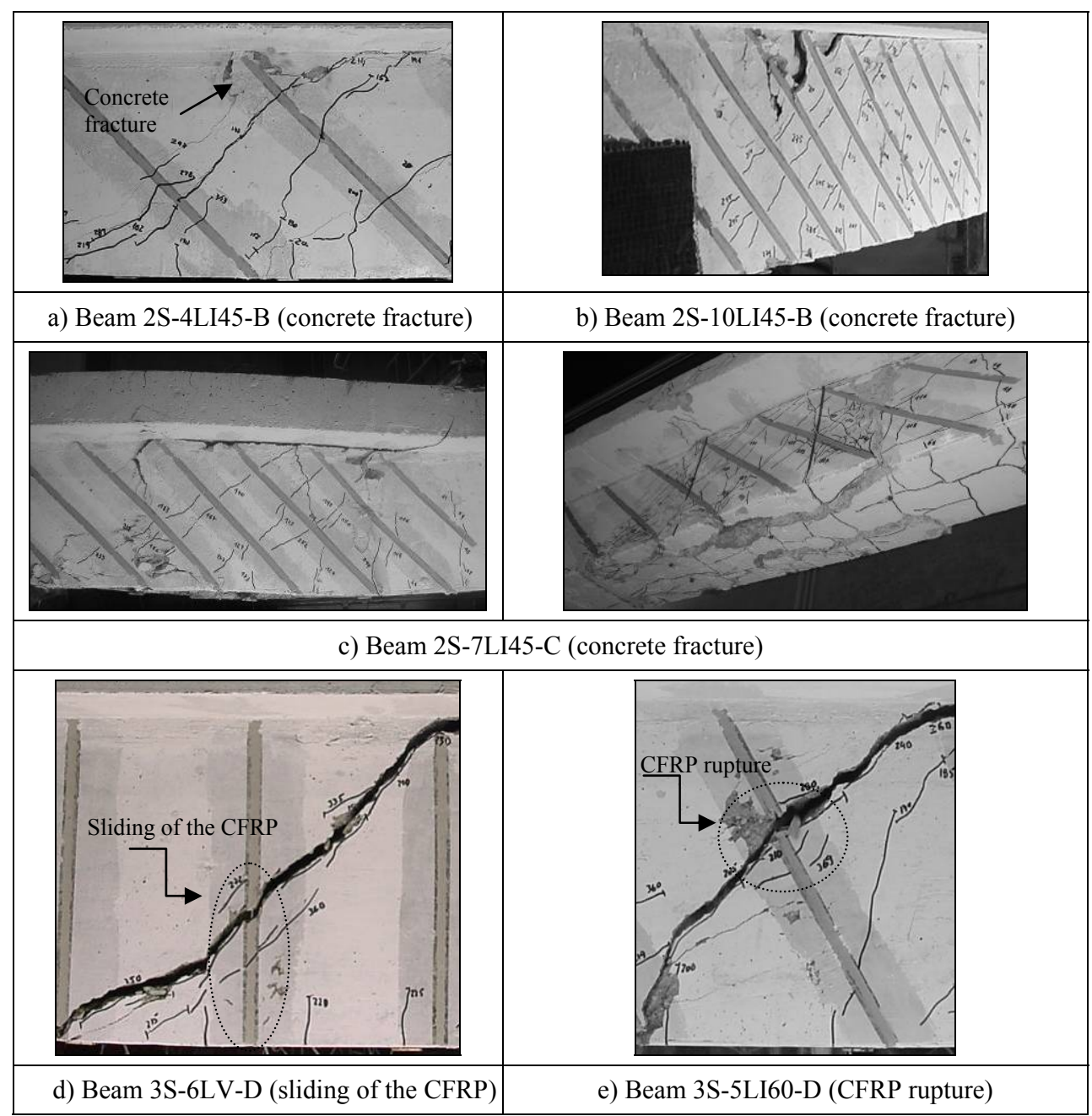

Fig. 5 - Failure modes of the RC beams shear strengthened with NSM CFRP laminates.

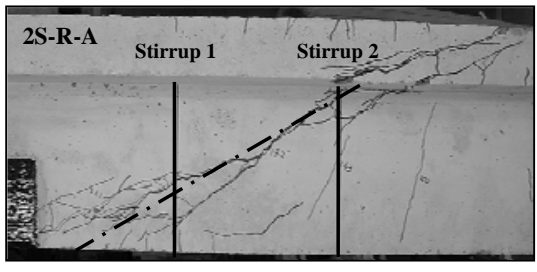

a)
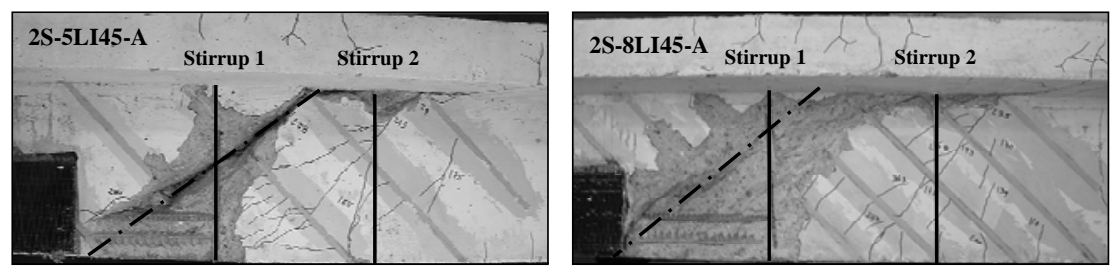

b)

Fig. 6 - Mobilization of steel stirrups crossing the shear failure crack: a) 2S-R-A reference beam, b) 2S-5LI45-A and 2S-8LI45-A strengthened beams. 


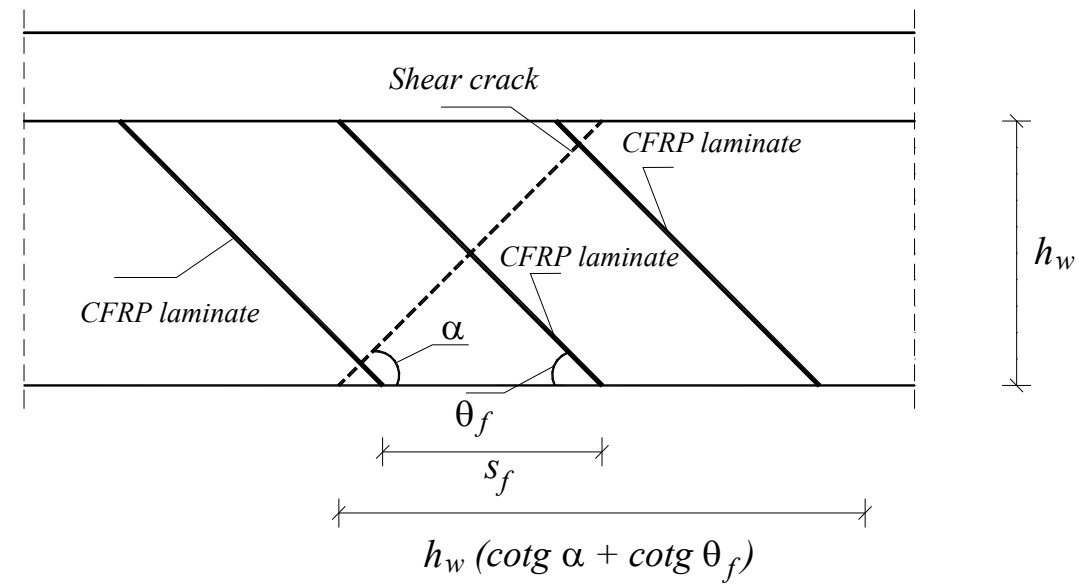

Fig. 7 - Data for the analytical definition of the effective strain of the CFRP.
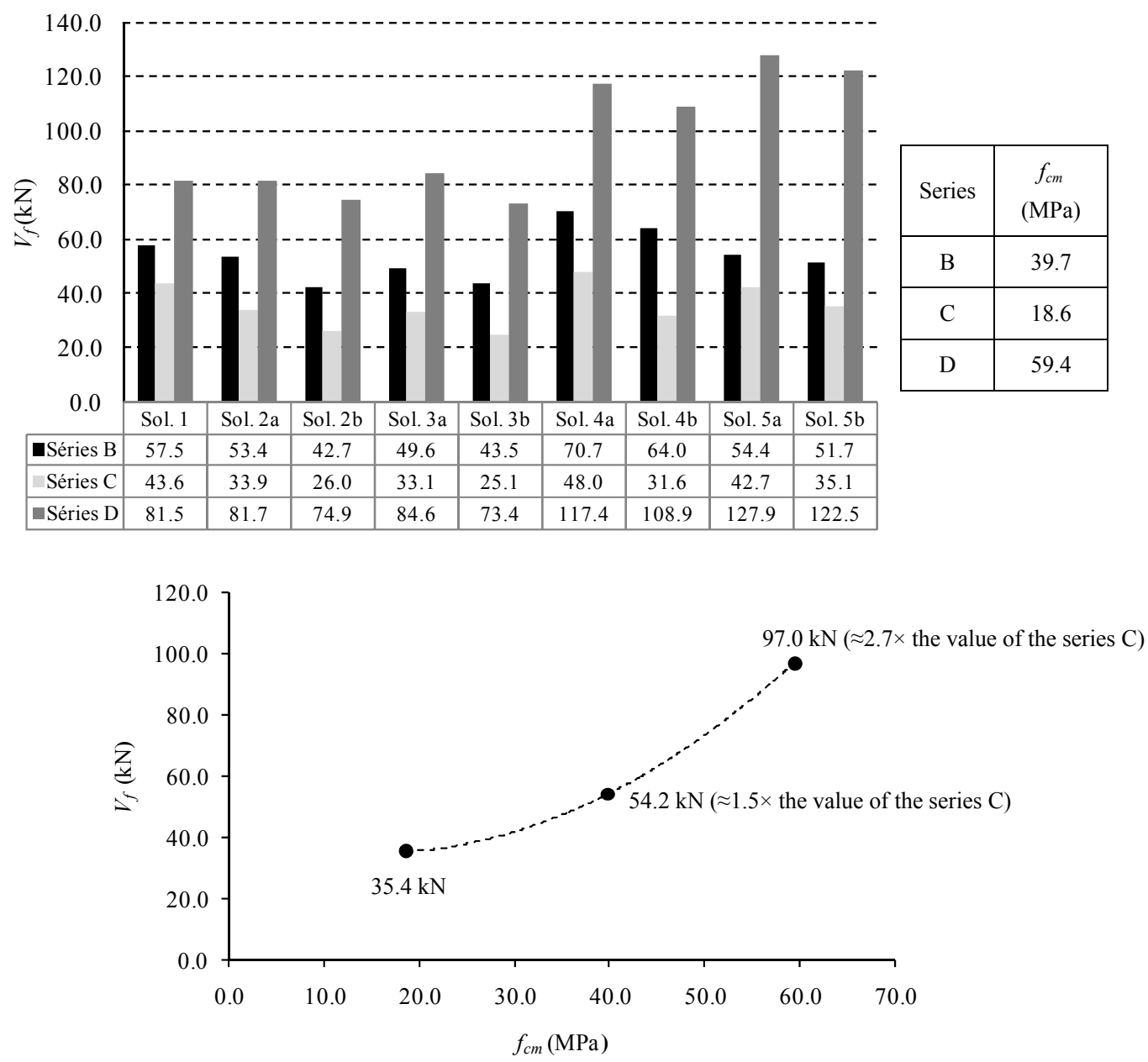

Fig. 8 - Influence of the concrete strength in the effectiveness of the NSM shear strengthening technique using CFRP laminates. 

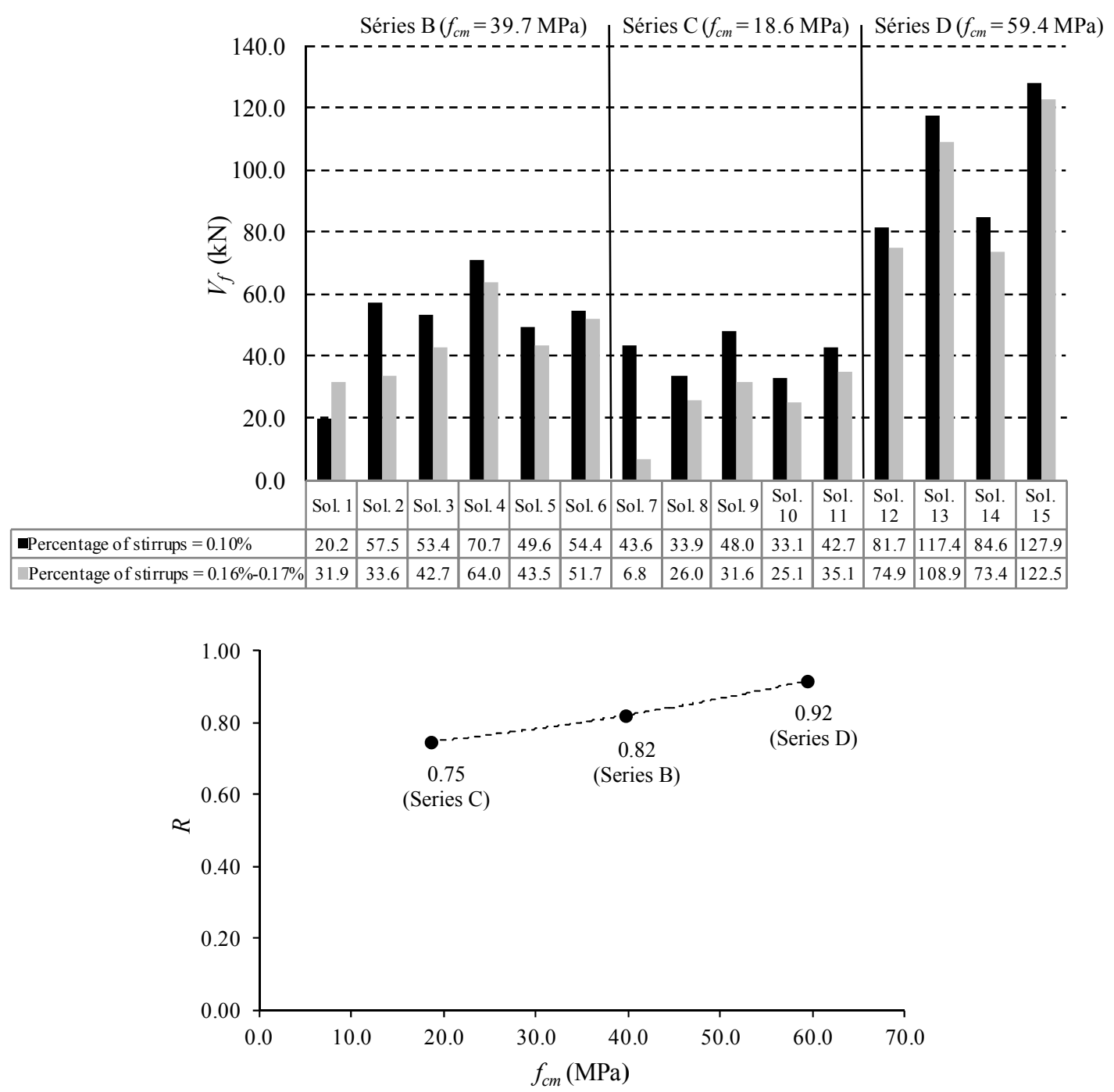

Fig. 9 - Influence of the percentage of existing steel stirrups in the effectiveness of the NSM shear strengthening technique using CFRP laminates.

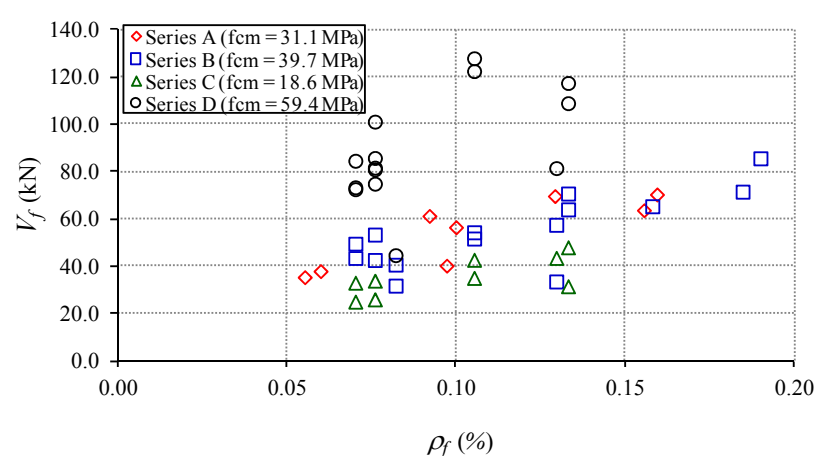

a)

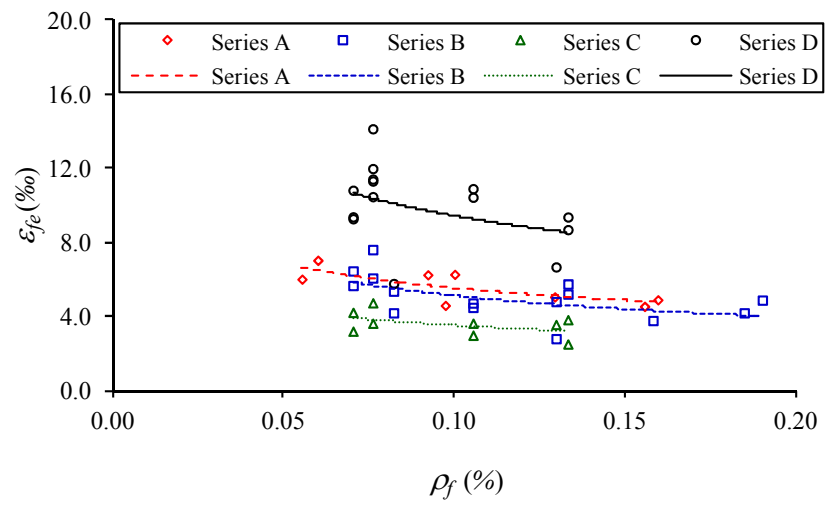

b)

Fig. 10 - Influence of the percentage of the CFRP in the effectiveness of the NSM shear strengthening technique using CFRP laminates. 


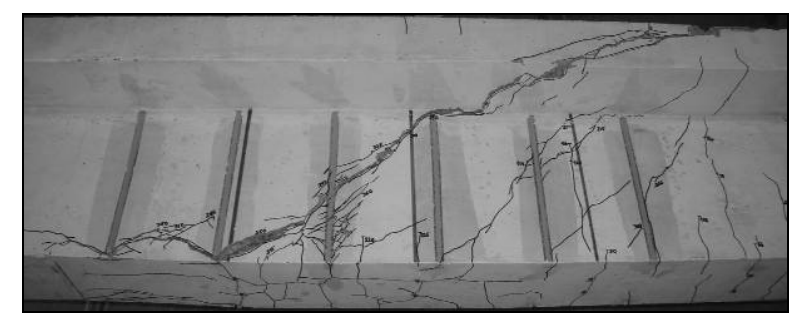

CFRP strengthening configuration with vertical laminates $\left(\rho_{f}=0.08 \%\right)$

a)

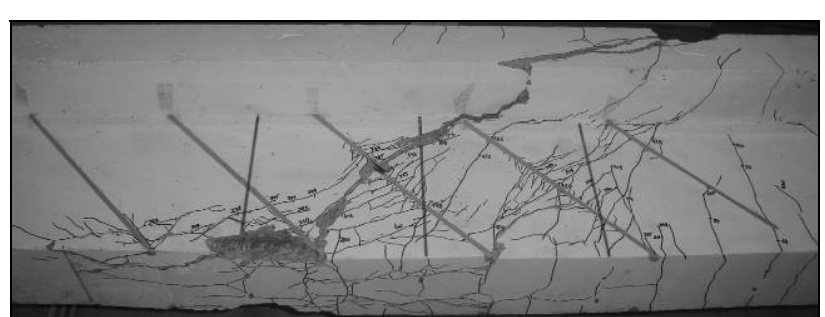

CFRP strengthening configuration with inclined laminates $\left(\rho_{f}=0.08 \%\right)$

b)

Fig. 11 - RC beams shear strengthened with: a) vertical and b) inclined laminates.

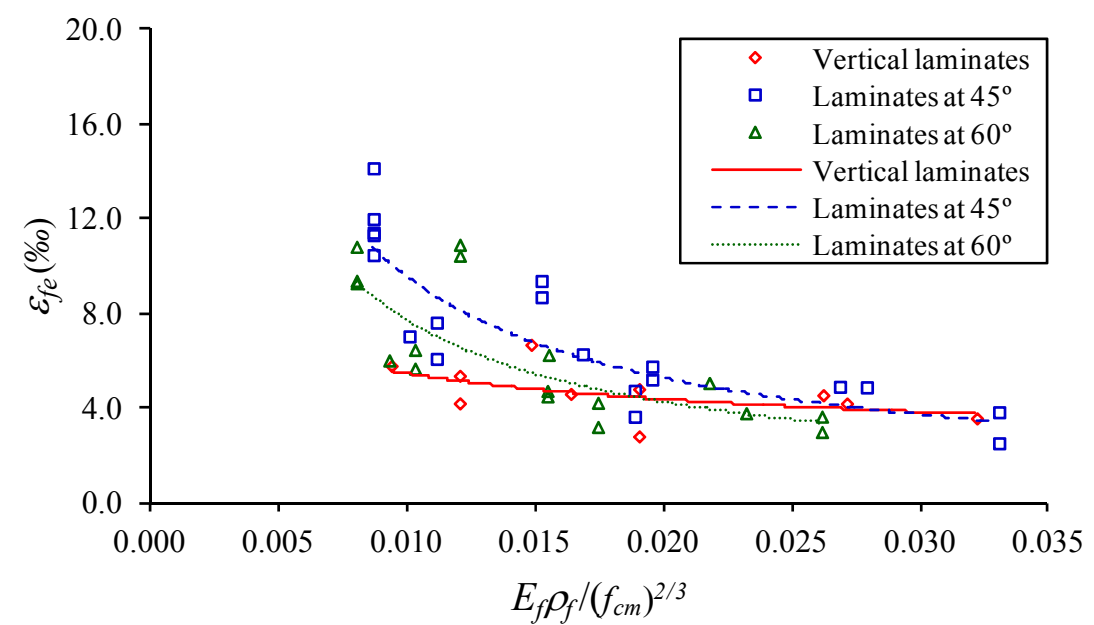

Fig. 12 - Influence of the orientation of the CFRP in the effectiveness of the NSM shear strengthening technique using CFRP laminates. 


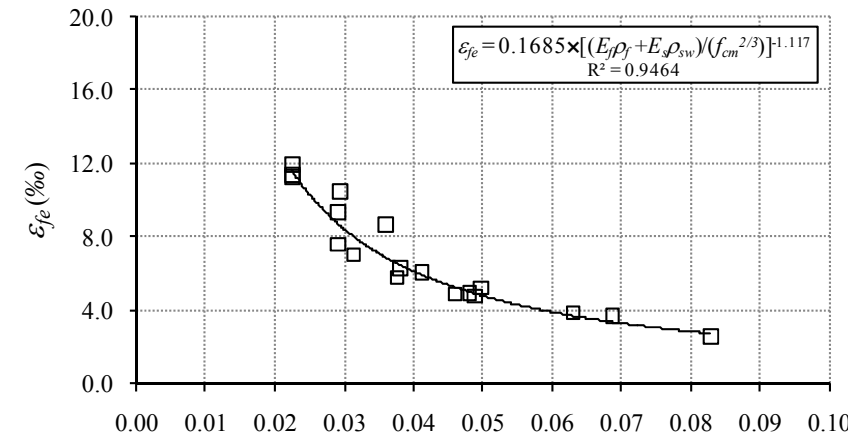

$\left(E_{f} \rho_{f}+E_{s} \rho_{s w}\right) /\left(f_{c m}{ }^{2 / 3}\right)$

a) Laminates at $45^{\circ}$

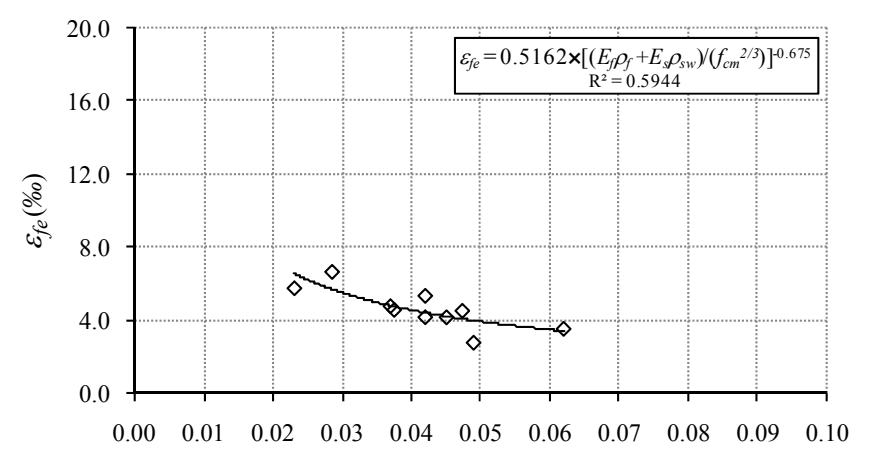

$\left(E_{f} \rho_{f}+E_{s} \rho_{s w}\right) /\left(f_{c m}^{2 / 3}\right)$

c) Vertical laminates

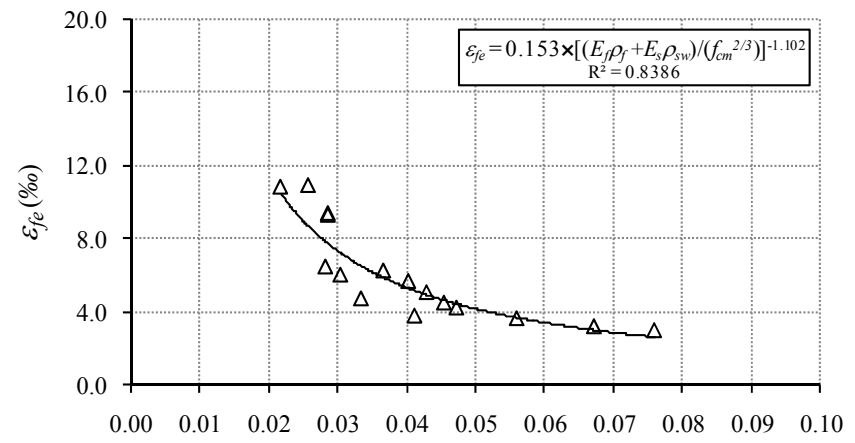

$\left(E_{f} \rho_{f}+E_{s} \rho_{s w}\right) /\left(f_{c m}{ }^{2 / 3}\right)$

b) Laminates at $60^{\circ}$

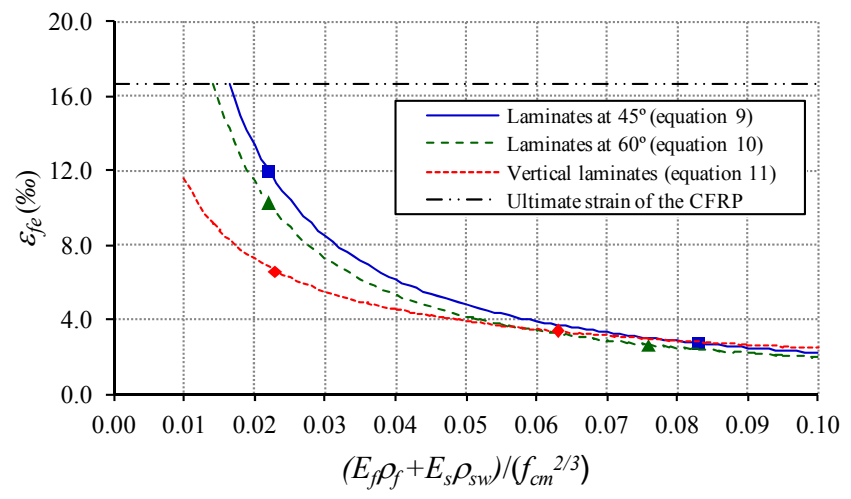

d)

Fig. 13 - Effective strain of the CFRP $\left(\varepsilon_{f e}\right) v s\left(E_{f} \rho_{f}+E_{s} \rho_{s w}\right) /\left(f_{c m}{ }^{2 / 3}\right)$

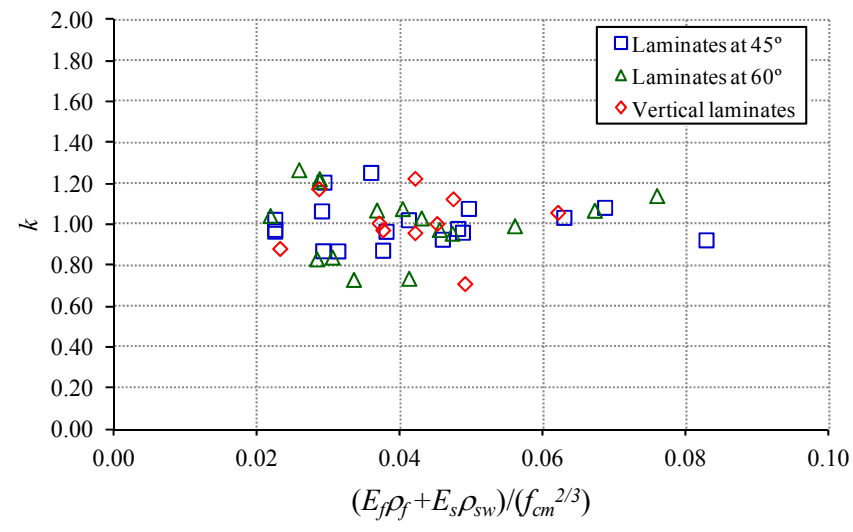

a)

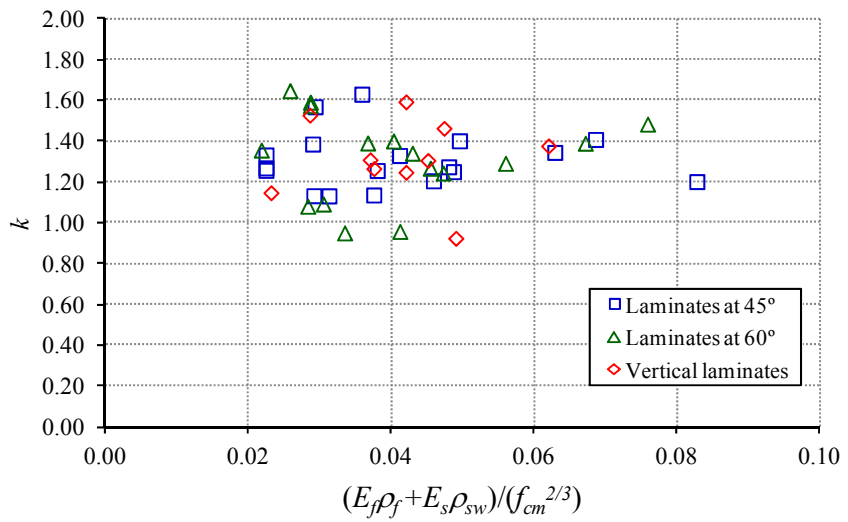

b)

Fig. 14 - Values of the $k$ parameter for all the analyzed shear strengthened RC beams: a) with $\gamma_{f}=1.0$; b) with $\gamma_{f}=1.3$. 


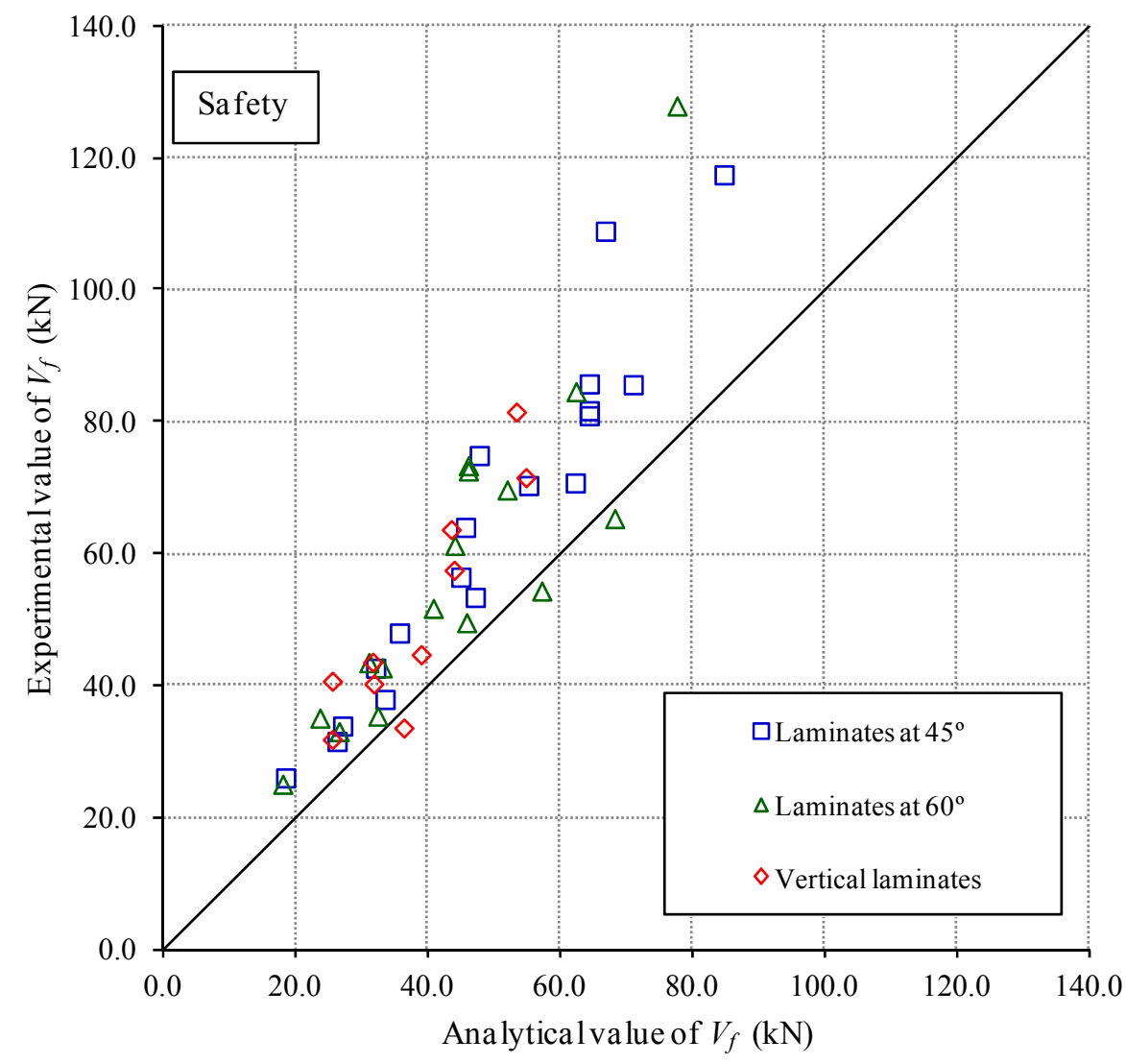

Fig. 15 - Comparison between the experimental and analytical values of the CFRP contribution for the shear resistance $\left(V_{f}\right)$. 